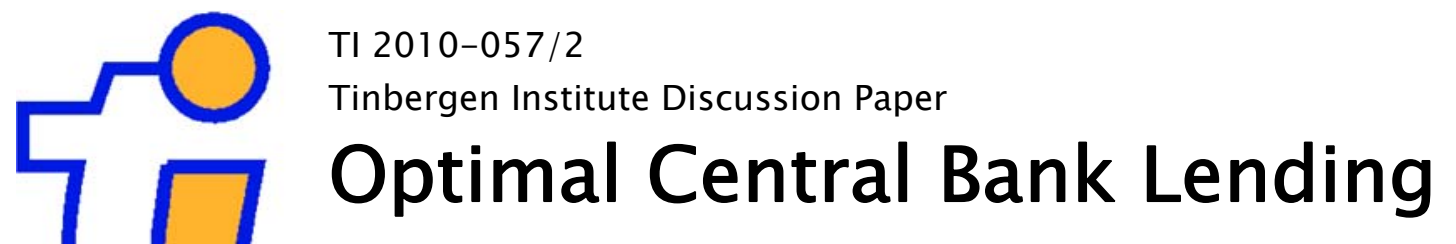

Andreas Schabert

University of Dortmund. 


\section{Tinbergen Institute}

The Tinbergen Institute is the institute for economic research of the Erasmus Universiteit Rotterdam, Universiteit van Amsterdam, and Vrije Universiteit Amsterdam.

Tinbergen Institute Amsterdam

Roetersstraat 31

1018 WB Amsterdam

The Netherlands

Tel.: +31(0)205513500

Fax: $+31(0) 205513555$

Tinbergen Institute Rotterdam

Burg. Oudlaan 50

3062 PA Rotterdam

The Netherlands

Tel.: + $31(0) 104088900$

Fax: $+31(0) 104089031$

Most TI discussion papers can be downloaded at http://www.tinbergen.nl. 


\title{
Optimal Central Bank Lending ${ }^{1}$
}

\author{
Andreas Schabert ${ }^{2}$ \\ TU Dortmund University and University of Amsterdam
}

This version: June 14, 2010

\begin{abstract}
We analyze optimal monetary policy in a sticky price model where the central bank supplies money outright via asset purchases and lends money temporarily against collateral. The terms of central bank lending affect rationing of money and impact on macroeconomic aggregates. The central bank can set the policy rate and its inflation target in a way that implements the first best long-run allocation, which is impossible if money were supplied in a lump-sum way (as commonly assumed). Efficient central bank lending further increases gains from macroeconomic stabilization beyond pure interest rate policy. This requires departing from a "Treasuriesonly" regime.
\end{abstract}

JEL classification: E4; E5; E32.

Keywords: Optimal monetary policy, central bank instruments, collateralized lending, liquidity premium, inflation

\footnotetext{
${ }^{1}$ We are grateful to Aleks Berentsen, Christian Beyer, Kai Carstensen, Wouter den Haan, Markus Hoermann, Gerhard Illing, Leo Kaas, Yvan Lengwiler, and Christian Stoltenberg and other seminar participants at the LMU Munich, University of Amsterdam, University of Basel, University of Bonn, and University of Konstanz for helpful comments and suggestions.

${ }^{2}$ University of Dortmund, Vogelpothsweg 87, 44227 Dortmund, Germany. Phone: +49 2317553182. Email: andreas.schabert@udo.edu.
} 


\section{Introduction}

The recent financial crisis has led the US Federal Reserve to set the policy rate close to its zero lower bound. It further introduced several lending facilities and direct asset purchases, which eased access to reserves in a way that led to a doubling of its balance sheet after September 2008. These policies demonstrate that there are more instruments available for central banks than the pre-crisis view on monetary policy has suggested by its focus on pure interest rate policy. In contrast to the latter view, central banks usually do not accommodate money demand in an unrestricted way. The Federal Reserve, for instance, has created a structural deficiency, i.e. "permanent additions to the supply of reserve balances that are somewhat less than the total need", and has additionally lent money in open market operations via repurchase agreements (repos), which are essentially collateralized loans. ${ }^{3}$ Hence, by relaxing collateral requirements or by direct asset purchases it can ease rationing of money supply, which has been thought to be effective during the recent crisis by reducing interest rate spreads and facilitating private sector credit flows (see Blinder, 2010, and Goodfriend, 2010).

This raises the questions if rationing of money can be justified in terms of welfare and how it should be used in non-crisis times. Economic theory has however not considered the role of money rationing via collateralized central bank lending for the optimal conduct of monetary policy. This paper aims to fill this gap. It will be shown that a central bank can enhance welfare by employing additional instruments that are neither considered in stylized textbook models (see Woodford, 2003) nor in larger models developed for estimation purposes (see Smets and Wouters, 2007, or Christiano et al., 2010).

For the analysis of optimal monetary policy we apply a model that accounts for the fact that money supply is mainly conducted in form of asset purchases and collateralized loans (repos) via open market operations. ${ }^{4}$ Given that we depart from the standard assumption of lump-sum money supply, private sector holdings of securities that are eligible for outright

\footnotetext{
${ }^{3}$ See Fedpoints "Open Market Operations" (http://www.newyorkfed.org/aboutthefed/fedpoint/fed32.html) and "Repurchase and Reverse Repurchase Transactions" (http://www.newyorkfed.org/aboutthefed/fedpoint/ fed04.html). Similarly, the European Central Bank applies "allotment rates" in open market operations.

${ }^{4}$ The framework relates to Reynard and Schabert's (2010) model, which has been used to explain the systematic difference between the policy rate and the Euler rate found by Canzoneri et al. (2007) and Atkeson and Kehoe (2009).
} 
sales or repurchase agreements matter for the access to money. The eligibility of assets for open market operations will affect their prices in an arbitrage-free equilibrium through (il-)liquidity premia. By changing the terms of lending, the central bank alters access to money and affects the spreads between interest rates on different assets and the policy rate, i.e. the price of money in terms of eligible assets. It can thereby impact on financial markets and macroeconomic aggregates beyond the effects of pure interest rate policy.

Since we do not aim to model a financial crises, we focus on central bank lending against collateral that is free of default risk, which accords to common central bank practice. ${ }^{5}$ While fully eligible assets, e.g. short-term government bonds, are priced at an interest rate that closely follows the policy rate, interest rates on non-eligible securities, like on corporate bonds, exceed the policy rate by a liquidity premium. Thus, a positive corporate bond spread can exist in an arbitrage-free equilibrium even without credit-default risk, ${ }^{6}$ consistent with empirical evidence (see Longstaff et al., 2005, or Covitz and Downing, 2007). Accepting corporate debt as collateral will then reduce the spread by increasing their liquidity/resaleability. Hence, changing the terms of central bank lending affects interest rate spreads via liquidity premia in accordance with empirical evidence on the effects of recently introduced Fed lending facilities (see Fleming et al., 2010, and Sarkar and Shrader, 2010).

The model accounts for frictions that are typically considered in the (New Keynesian) literature on optimal monetary policy, which facilitates comparisons with related studies. Specifically, we allow for prices to be set in an imperfectly flexible way and for cost-push shocks, modelled as disturbances to wage mark-ups. Pure interest rate policy, i.e. interest rate setting associated with endogenous lump-sum money supply, cannot implement the first best allocation and leads to the well-known trade-off between stabilizing prices and closing output-gaps (see e.g. Clarida et al., 1999). In contrast, we consider that access to money is effectively constrained by private sector holdings of eligible assets, predominantly

\footnotetext{
${ }^{5}$ The US Federal Reserve has for example mainly accepted securities issued by the treasury and federal agencies, which meet high credit quality standards (see e.g. Meulendyke, 1998). In section 5, we briefly discuss the case of collateral associated with default risk.

${ }^{6}$ The absence of imperfections in private financial intermediation is a main difference between our setup and the models developed by Curdia and Woodford (2010), Gertler and Karadi (2010), and Gertler and Kiyotaki (2010), where central bank (direct) lending matters due to the existence of costs of private intermediation.
} 
short-term government bonds. Given that money is rationed, easing or restricting the terms of lending serves as an effective instrument in addition to setting the policy rate. To be more precise, the central bank can additionally use money supply policy, i.e. the maximum amount of money supplied against collateral, and collateral standards, i.e. the ratio of public to corporate debt held under repos, to affect prices and macroeconomic aggregates. ${ }^{7}$

To motivate issuance of corporate debt, we assume that firms rely on loans for working capital, which provides an additional transactions friction, since positive loan rates increase marginal costs of production. We focus on the (empirically relevant) case where the policy rate is set by the central bank below the standard consumption Euler rate, i.e. the interest rate on non-eligible assets. Eligible assets then exhibit an interest rate that closely follows the policy rate and private agents economize on holding eligible assets, since they offer a pecuniary rate of return that is smaller than the interest rate on non-eligible assets. Nevertheless, eligible assets will be held in an arbitrage-free equilibrium given that they provide liquidity services as an imperfect substitute for money. Regardless of the supply of potentially eligible assets, which, for example, depends on short-term government borrowing, the central bank can independently control money supply and thus long-run inflation by adjusting its terms of lending.

Within this framework, we first examine the long-run effects of monetary policy. We show that the central bank can implement the first best allocation in the long-run, which requires $i$.) targeting long-run price stability to avoid price dispersion, $i i$.) accepting all loans as collateral such that the loan rate equals the policy rate, and iii.) setting the policy rate at its zero lower bound to eliminate the transactions friction. ${ }^{8}$ In contrast, if loans are not eligible, the loan rate exceeds the policy rate such that costs of borrowing are raised and production is inefficiently low. Likewise, the first-best can also not be implemented under a standard monetary policy regime, where the policy rate equals the Euler rate and is linked to inflation (by the Fisher equation) such that $i$.) and $i i i$.) are incompatible.

A similar principle applies for short-run stabilization policy. In contrast to the standard

\footnotetext{
${ }^{7}$ Money supply policy and collateral standards correspond to the terms quantitative easing and qualitative easing used in Bernanke et al. (2004). These additional instruments are further related, though not identical (see section 5), to the instruments examined in Goodfriend (2010) and Curdia and Woodford (2010).

${ }^{8}$ Notably, interest rates on non-eligible assets and thus opportunity costs of money holdings are still positive (implying a well-defined money demand) when the policy rate is at the zero lower bound.
} 
case of pure interest rate policy, the central bank can use money supply policy and collateral standards to eliminate welfare costs of short-run fluctuations. The effectiveness of its instruments requires accepting at least some (but not all) loans as collateral. ${ }^{9}$ The central bank can then directly control the loan rate by setting the policy rate, which serves as an effective tool to eliminate distortionary changes in firms' marginal costs. At the same time, it can stimulate or dampen aggregate demand by changing its terms of lending. Specifically, by using all instruments, the central bank can simultaneously off-set cost-push disturbances and stabilize the price level by manipulating aggregate demand, which is impossible in the standard case of pure interest rate policy (see Woodford, 2003, or Ravenna and Walsh, 2006). Hence, monetary policy can enhance welfare and overcome the above-mentioned trade-off by flexibly rationing the supply of money.

The difference to a standard pure interest rate policy regime is most evident for the policy rate response to macroeconomic shocks. When the economy is hit by a positive cost-push (wage mark-up) shock, the policy rate would have to rise under a pure interest rate policy regime to reduce inflationary pressure by depressing aggregate demand (see Clarida et al., 1999). Under an optimal central bank lending regime, the policy rate has to be lowered to off-set the cost-push effect of the wage mark-up shock by reducing the costs of borrowing. At the same time, the terms of lending need to be restricted to stabilize money supply and thus aggregate demand in face of a lower price of money. Likewise, under both regimes the policy rate will respond to productivity shocks in opposite directions.

The paper is related to several strands in the literature. It relates to studies on optimal monetary policy under sticky prices and transactions frictions associated with money demand, like Kahn et al. (2004), Ravenna and Walsh (2006), and Christiano et al. (2010), showing that the central bank should predominantly stabilize prices and deviate from the Friedman rule. Optimal policy is also mainly characterized by price stability when prices are sticky and taxes are distortionary, even though inflation serves as a substitute for taxation (see Schmitt-Grohe and Uribe, 2004, and Benigno and Woodford, 2004). While the

\footnotetext{
${ }^{9}$ Though the US Federal Reserve mainly accepted "Treasuries only" in the pre-crises period, corporate debt securities - like commercial papers - have also been considered as substitutes for treasury debt in case of "large budget surpluses and the associated steep reductions in Treasury debt" (see Federal Reserve System Study Group on Alternative Instruments for System Operations, 2002).
} 
allocation under optimal policy depends on the degree of price stickiness in these studies, Correia et al. (2008) show that the same allocations can be implemented regardless of price stickiness when sufficiently many tax instruments are available. This corresponds to our result that the optimal allocation can be implemented under flexible prices as well as under sticky prices when monetary instruments in addition to the policy rate are used. In contrast to the case considered by Adao et al. (2003), where the central bank simultaneously controls the policy rate and lump-sum supply money, the long-run first best allocation can be implemented by the central bank in our framework.

The paper also relates to three recent studies on central banks acting as a direct lender to the private sector, such that private debt is held outright by the central bank rather than temporarily as collateral. Curdia and Woodford (2010) analyze monetary policy in a sticky price model with two types of households (borrower and lender) and imperfections in private financial intermediation. A central bank's "credit policy" (i.e. unsecured lending to the private sector) is associated with costs that differ from private costs of intermediation, and can be beneficial at times of unusual financial distress. They conclude that the central bank should apply a pure interest rate policy under normal circumstances, which contrasts the results in our paper. Gertler and Karadi (2009) develop a model without transactions frictions, where central bank credit policy can also matter due to costs of financial intermediation. While private intermediaries face balance sheets constraints, the central bank can inelastically raise funds, such that central bank credit policy can enhance welfare during financial crises. Applying a purely real framework, which is based on Gertler and Karadi's (2009) model augmented by idiosyncratic investment risks, Gertler and Kiyotaki (2010) also find that credit policy is beneficial in crises situations when private intermediaries are financially constrained. ${ }^{10}$

The paper is organized as follows. Section 2 presents the model. In section 3, we examine the long-run effects of monetary policy. In section 4, we describe optimal stabilization policy under flexible prices and sticky prices. Section 5 discusses the impact of default risk and direct central bank lending. Section 6 concludes.

\footnotetext{
${ }^{10}$ In section 5, we discuss how credit policy differs from central bank lending as specified in our model.
} 


\section{The model}

In this section, we develop a model that accounts for frictions, which are standard in the New Keynesian literature on monetary policy. In particular, we account for sticky prices (à la Calvo, 1983), cost push shocks (i.e. time varying wage mark-ups), and transactions frictions. Money is required by households as a means of payment in the goods market and by firms to finance the wages in advance. ${ }^{11}$ The central bank supplies money either via outright purchases of assets or by lending temporarily against collateral, for which it accepts government bonds or corporate loans. We neglect default risk and restrict our attention to the case where the central bank treats all securities of each type in an identical way (see section 5 for a discussion of default risk and directed lending). The central bank sets the price of money in open market operations, it can decide on the rationed quantity of money (i.e. the amount of accepted assets), and the collateral standards (i.e. the type of eligible assets). There are further intermediate goods producing firms, who exist for one period and employ labor, retailers, who set their prices in an imperfectly flexible way, and the fiscal authority, who issues short-term debt.

\section{$2.1 \quad$ Timing of events}

Households, indexed with $i \in[0,1]$, enter a period $t$ with money, government bonds, and household debt, $M_{i, t-1}^{H}+B_{i, t-1}+D_{i, t-1}$. At the beginning of the period, aggregate shocks are realized. Then, the central bank sets its instruments, i.e. it announces the fractions of government bonds and corporate loans that are accepted in open market operations, $\kappa_{t}^{B} \in(0,1]$ and $\kappa_{t} \in[0,1]$, and the policy rate $R_{t}^{m} \geq 1$. The remainder of the period can be divided into four subperiods.

1. The labor market opens, where a perfectly competitive intermediate goods producing firm $j$ hires workers $n_{j, t}$. We assume that it has to pay workers their wages in cash before the goods are sold. Since it does not hold any financial wealth, it has to borrow

\footnotetext{
${ }^{11}$ The model relates to Reynard and Schabert (2010) model with open market operations for the case of "Treasuries-only". This model mainly differs from theirs by considering a standard working capital constraint, non-treasury collateral, and, most importantly, additional monetary policy instruments beyond pure interest rate policy.
} 
cash. Firm $j$ thus faces the cash constraint

$$
L_{j, t} / R_{j, t}^{L} \geq P_{t} w_{t} n_{j, t}
$$

where $w_{t}$ denotes the real wage rate, $P_{t}$ denotes the final goods price, $L_{j, t} / R_{j, t}^{L}$ the amount received by the borrowing firm. Firm $j$ commits to repay the amount $L_{j, t}$ at the end of the period, such that $R_{j, t}^{L}$ is the interest on the intra-period loan. Lender then sign loan contracts with all firms, taking into account that a fraction $\kappa_{t}$ of all loans can be used as collateral for repurchase agreements.

2. The money market opens where the central bank sales or purchases assets outright or under repurchase agreements for money at the rate $R_{t}^{m}$. In contrast to household debt, corporate loans and government bonds can be eligible, where only the latter can be purchased outright by the central bank. In period $t$, household $i$ receives money (injections) from the central bank, $I_{i, t}=M_{i, t}^{H}-M_{i, t-1}^{H}+M_{i, t}^{R}+M_{i, t}^{L}$, where $M_{i, t}^{H}-M_{i, t-1}^{H}$ is the amount of money received from the central bank's outright bond purchases, and $M_{i, t}^{R}$ and $M_{i, t}^{L}$ denote money received in repos for bonds and loans. Specifically, the central bank supplies money against a randomly selected fraction $\kappa_{t}^{B}$ of bonds and a randomly selected fraction $\kappa_{t}$ of loans, $M_{i, t}^{H}-M_{i, t-1}^{H}+M_{i, t}^{R} \leq \kappa_{t}^{B}\left(B_{i, t-1} / R_{t}^{m}\right)$ and $M_{i, t}^{L} \leq \kappa_{t}\left(L_{i, t} / R_{t}^{m}\right)$, such that $I_{i, t}$ is constrained by

$$
I_{i, t} \leq \kappa_{t}^{B}\left(B_{i, t-1} / R_{t}^{m}\right)+\kappa_{t}\left(L_{i, t} / R_{t}^{m}\right) .
$$

After receiving money injections from the central bank, household $i$ delivers the amount $L_{i, t} / R_{t}^{L}$ to firms according to the loan contract, while it can refinance a fraction $\kappa$ of loans. Its holdings of money, bonds, and loans are then $M_{i, t-1}^{H}+I_{i, t}-\left(L_{i, t} / R_{t}^{L}\right)$, $B_{i, t-1}-\Delta B_{i, t}^{c}$, and $L_{i, t}-L_{i, t}^{R}$, where $\Delta B_{i, t}^{c}$ are bonds received by the central bank and $L_{i, t}^{R}$ are loans under repos, such that $I_{i, t}=\left(\Delta B_{i, t}^{c} / R_{t}^{m}\right)+\left(L_{i, t}^{R} / R_{t}^{m}\right)$.

3. Wages are paid, and intermediate as well as final goods are produced. Then, the goods market opens, where final goods can only be bought with money. Hence, household $i$ faces the cash-in-advance constraint

$$
P_{t} c_{i, t} \leq I_{i, t}+M_{i, t-1}^{H}-\left(L_{i, t} / R_{t}^{L}\right)+P_{t} w_{i, t} n_{i, t} .
$$


Final goods producing firms receive cash for their sales, and pay for the intermediate goods. Both further pay out dividends to their owners (households), which sum up to $P_{t} \delta_{i, t}$ for household $i$, such that its money holdings are $M_{i, t-1}^{H}+I_{i, t}-\left(L_{i, t} / R_{t}^{L}\right)+$ $P_{t} w_{i, t} n_{i, t}-P_{t} c_{i, t}+P_{t} \delta_{i, t}$.

4. Repurchase agreements are settled, i.e. household $i$ buys back government bonds $B_{i, t}^{R}$ and corporate debt $L_{i, t}^{R}$ from the central bank with money. Household $i$ 's bond and money holdings are therefore given by $\widetilde{B}_{i, t}=B_{i, t-1}-\Delta B_{i, t}^{c}+B_{i, t}^{R}$ and $\widetilde{M}_{i, t}=$ $I_{i, t}+M_{i, t-1}^{H}-\left(L_{i, t} / R_{t}^{L}\right)+P_{t} w_{i, t} n_{i, t}-P_{t} c_{i, t}+P_{t} \delta_{i, t}-B_{i, t}^{R}-L_{i, t}^{R}$. In the asset market, loans are repaid and households receive payoffs from maturing assets as well as government transfers $P_{t} \tau_{i, t}$. Further, the government issues new bonds at the price $1 / R_{t}$. Household $i$ can thus carry wealth into $t+1$ in form of bonds, state-contingent claims, or money, such that its asset market constraint is

$$
\left(B_{i, t} / R_{t}\right)+E_{t}\left[q_{t, t+1} D_{i, t}\right]+M_{i, t}^{H} \leq \widetilde{B}_{i, t}+D_{i, t-1}+\widetilde{M}_{i, t}+L_{i, t}+P_{t} \tau_{i, t},
$$

where $q_{t, t+1}$ denotes a stochastic discount factor (see section 2.3). The central bank reinvests its payoffs from maturing bonds in new government bonds and leaves money supply uncahnged, $\int \widetilde{M}_{i, t} d i=\int M_{i, t}^{H} d i$.

\section{$2.2 \quad$ Firms}

There is a continuum of identical intermediate goods producing firms indexed with $j \in$ $[0,1] .{ }^{12}$ They exist for one period, are perfectly competitive, and are owned by the households. A firm $j$ distributes profits to the owners and hires the aggregate labor input $n_{j, t}$ at a common rate rate $w_{t}$. We assume that wages have to be paid in advance, i.e. before goods are sold. For this, firm $j$ borrows cash $L_{j, t}$ from households at the price $1 / R_{j, t}^{L}$ and repays the loan at the end of the period. Hence, firm $j$ faces the working capital constraint (1).

It then produces the intermediate good according to the production function $I O_{j, t}=$ $a_{t} n_{j, t}^{\alpha}$, where $\alpha \in(0,1)$ and $a_{t}$ is a stochastic productivity level with an unconditional mean equal to one, and sells it to retailers who pay them in cash (after they have received house-

\footnotetext{
${ }^{12}$ In section 5.1, we consider the case where intermediate goods producing firms face idiosyncratic productivity shocks.
} 
holds' money for goods). With these revenues, it repays intra-period loans. We follow large parts of the literature on New Keynesian macroeconomics, and allow for the elimination of long-run distortions by introducing a constant subsidy (see Woodford, 2003). In particular, we assume that intermediate firms receive a fixed wage subsidy $\tau^{n}$ after it paid the wages. The problem of a profit-maximizing firm $j$ is then given by

$$
\max \left(P_{J, t} / P_{t}\right) a_{t} n_{j, t}^{\alpha}-\left(1-\tau^{n}\right) w_{t} n_{j, t}-l_{j, t}\left(R_{j, t}^{L}-1\right) / R_{j, t}^{L}, \text { s.t. (1), }
$$

where $l_{j, t}=L_{j, t} / P_{t}$ and $P_{J, t}$ denotes the price for the intermediate good. Throughout the analysis, we restrict our attention to the case, where intermediate goods producing firms borrow not more then required to pay wages, such that (1) holds with equality. Then, the following conditions determine labor demand and the volume of loans,

$$
\begin{aligned}
\left(P_{J, t} / P_{t}\right) a_{t} \alpha n_{j, t}^{\alpha-1} & =\left(1-\tau^{n}\right) w_{t} R_{j, t}^{L} \\
l_{j, t} / R_{j, t}^{L} & =w_{t} n_{j, t}
\end{aligned}
$$

while remaining profits are transferred to the owners in a lump-sum way. Condition (6) shows that the working capital constraint can distort labor demand through the costs of borrowing $\left(R_{t}^{L} \geq 1\right)$. Since intermediate goods producing firms are ex-ante identical, they will only differ with regard to their labor demand, if they face different costs of borrowing (6). This would, for example, be the case, if lenders perceive loans of different firms as imperfect substitutes. For the benchmark version of the model, we disregard this possibility and assume that the central bank treats all firms in an ex-ante identical way, such that the cost of borrowing will be identical, $R_{j, t}^{L}=R_{t}^{L}$ (see section 5.2 for a discussion).

Monopolistically competitive retailers buy intermediate goods $I O_{t}=\int_{0}^{1} I O_{j, t} d j$ at the common price $P_{J, t}$. A retailer $k \in[0,1]$ relabels the intermediate good to $y_{k, t}$ and sells it at the price $P_{k, t}$ to perfectly competitive bundlers, who bundle the goods $y_{k, t}$ to the final consumption good $y_{t}$ with the technology, $y_{t}^{\frac{\varepsilon-1}{\varepsilon}}=\int_{0}^{1} y_{k, t}^{\frac{\varepsilon-1}{\varepsilon}} d k$. The cost minimizing demand for $y_{k, t}$ is then given by $y_{k, t}=\left(P_{k, t} / P_{t}\right)^{-\varepsilon} y_{t}$.

Retailers set their prices to maximize profits. Following Calvo (1983), we assume that each period a measure $1-\phi$ of randomly selected retailers may reset their prices independently of the time elapsed since the last price setting, while a fraction $\phi \in[0,1)$ of retailers 
do not adjust their prices. Maximizing discounted future profits, a fraction of $1-\phi$ retailers set their price $P_{k, t}$ to maximize the expected sum of discounted future. For $\phi>0$, the first order condition for $P_{k t}$ is given by

$$
P_{k, t}=\frac{\varepsilon}{\varepsilon-1} \frac{E_{t} \sum_{s=0}^{\infty}(\phi \beta)^{s} c_{t+s}^{-\sigma} y_{t+s} P_{t+s}^{\varepsilon} m c_{t+s}}{E_{t} \sum_{s=0}^{\infty}(\phi \beta)^{s} c_{t+s}^{-\sigma} y_{t+s} P_{t+s}^{\varepsilon-1}}
$$

where $m c_{t}=P_{J, t} / P_{t}$ denotes retailers' real marginal cost. Defining $\tilde{Z}_{t}=P_{k, t} / P_{t}$ and rewriting the denominator and numerator in a recursive way, condition (8) can be expressed as $\tilde{Z}_{t}=Z_{t}^{1} / Z_{t}^{2}$, where $Z_{t}^{1}=c_{t}^{-\sigma} y_{t} m c_{t}+\phi \beta E_{t} \pi_{t+1}^{\varepsilon} Z_{t+1}^{1}$ and $Z_{t}^{2}=c_{t}^{-\sigma} y_{t}+\phi \beta E_{t} \pi_{t+1}^{\varepsilon-1} Z_{t+1}^{2}$. Using the price index $P_{t}$ for the final consumption good, $P_{t}=\left(\int_{0}^{1} P_{k, t}^{1-\varepsilon} d k\right)^{1 /(1-\varepsilon)}$, and the demand constraint, $y_{k, t}=\left(P_{k, t} / P_{t}\right)^{-\varepsilon} y_{t}$, we obtain a law of motion for inflation depending on the firms' pricing decision $\tilde{Z}_{t}, 1=(1-\phi) \tilde{Z}_{t}^{1-\varepsilon}+\phi \pi_{t}^{\varepsilon-1}$ (see, Schmitt-Grohé and Uribe, 2006).

\subsection{Households}

There is a continuum of infinitely lived households indexed with $i \in[0,1]$. Households have identical asset endowments and identical preferences. Household $i$ maximizes the expected sum of a discounted stream of instantaneous utilities

$$
E \sum_{t=0}^{\infty} \beta^{t} u\left(c_{i, t}, n_{i, t}\right)
$$

where $E$ is the expectation operator conditional on the information set in the initial period, $\beta \in(0,1)$ is the subjective discount factor, and the instantaneous utility function is given by $u\left(c_{i, t}, n_{i, t}\right)=c_{i, t}^{1-\sigma}(1-\sigma)^{-1}-\chi n_{i, t}^{1+\eta}(1+\eta)^{-1}, \sigma>0$, and $\eta \geq 0$.

Households are assumed to monopolistically supply differentiated labor services $n_{i, t}$ that are transformed into aggregate labor input $n_{t}$ employed for the production of intermediate goods. The transformation is conducted via the aggregator $n_{t}^{1-1 / \zeta_{t}}=\int_{0}^{1} n_{i, t}^{1-1 / \zeta_{t}} d i$. We follow Smets and Wouters (2007) and assume that the elasticity of substitution between differentiated labor services $\vartheta_{t}>1$ varies exogenously over time. Cost minimization leads to the following demand for differentiated labor services $n_{i, t}$,

$$
n_{i, t}=\left(w_{i, t} / w_{t}\right)^{-\zeta_{t}} n_{t}, \quad \text { with } \quad w_{t}^{1-\zeta_{t}}=\int_{0}^{1} w_{i, t}^{1-\zeta_{t}} d i
$$

where $w_{i, t}$ and $w_{t}$ are the individual and the aggregate real wage rate, respectively. 
A household $i$ is initially endowed with money $M_{i,-1}^{H}$, government bonds $B_{i,-1}$, and privately issued debt $D_{i,-1}$. In each period, it supplies labor, consumes the final good, lends money to intermediate goods producing firms, trades with the central bank in open market operations, and reinvests in assets. Before household $i$ enters the goods market, where it relies on cash for goods purchases (see 3), it might lend money to firms. In addition to government bonds, it can eventually use a fraction of these loans to get additional money in open market operations (see 2). At beginning of the period, the central bank announces how many loans and bonds it will accept in open market operations $\left(\kappa_{t}\right.$ and $\left.\kappa_{t}^{B}\right)$, while it randomly selects them after households have signed the loan contracts. Hence, loans to ex-ante identical intermediate goods producing firms are perfect substitutes, such that households will demand the same loan rate for all firms.

In the goods market, household $i$ can use wages, money holdings net of lending, and additional cash from current period open market operations for its consumption expenditures (see 3). Before the asset market opens, repurchase agreements are settled and loans are repaid. In the asset market, household $i$ receives payoffs from maturing assets, buys bonds from the government, and borrows/lends using a full set of nominally state contingent claims. Dividing the period $t$ price of one unit of nominal wealth in a particular state of period $t+1$ by the period $t$ probability of that state gives the stochastic discount factor $q_{t, t+1}$. The period $t$ price of a random payoff $D_{j t}$ from investments in state contingent claims in period $t+1$ is then given by $E_{t}\left[q_{t, t+1} D_{j t}\right]$. Substituting out the stock of bonds and money held before the asset market opens, $\widetilde{B}_{i, t}$ and $\widetilde{M}_{i, t}$, in (4), the asset market constraint of household $i$ can thus be written as

$$
\begin{aligned}
& M_{i, t-1}^{H}+B_{i, t-1}+L_{i, t}\left(1-1 / R_{t}^{L}\right)+P_{t} w_{i, t} n_{i, t}+D_{i, t-1}+P_{t} \delta_{i, t}+P_{t} \tau_{i, t} \\
& \leq M_{i, t}^{H}+\left(B_{i, t} / R_{t}\right)+E_{t}\left[q_{t, t+1} D_{i, t}\right]+I_{i, t}\left(R_{t}^{m}-1\right)+P_{t} c_{i, t},
\end{aligned}
$$

while household $i^{\prime} s$ borrowing is restricted by the no-Ponzi game condition $\lim _{s \rightarrow \infty} E_{t} q_{t, t+s} D_{i, t+s} \geq$ 0 , as well as by $M_{i, t}^{H} \geq 0$ and $B_{i, t} \geq 0 .{ }^{13}$ The term $I_{i, t}\left(R_{t}^{m}-1\right)$ gives the costs of money acquired in open market operations. ${ }^{14}$ Maximizing (9) subject to (10), the open market con-

\footnotetext{
${ }^{13}$ The latter two constraints will not be binding throughout the analysis.

${ }^{14}$ Throughout the paper, we will restrict our attention to the case where the central bank will not withdraw
} 
straint (2), the goods market constraint (3), and the asset market constraints (11) and the borrowing constraints, for given initial values $M_{i,-1}, B_{i,-1}$, and $D_{i,-1}$ leads to the following first order conditions for consumption, working time, injections, and loans

$$
\begin{aligned}
c_{i, t}^{-\sigma} & =\lambda_{i, t}+\psi_{i, t} \\
\mu_{t} \chi n_{i, t}^{\eta} & =w_{t}\left(\lambda_{i, t}+\psi_{i, t}\right), \\
\psi_{i, t} & =\left(R_{t}^{m}-1\right) \lambda_{i, t}+R_{t}^{m} \eta_{i, t}, \\
R_{t}^{m}\left(\lambda_{i, t}+\eta_{i, t}\right) & =R_{t}^{L}\left(\lambda_{i, t}+\eta_{i, t} \kappa_{t}\right),
\end{aligned}
$$

where $\mu_{t}=\zeta_{t} /\left(\zeta_{t}-1\right)$ denotes the stochastic wage mark-up, $\lambda_{i, t}$ the multiplier for the asset market constraint, $\eta_{i, t}$ the multiplier on the open market constraint $\left(\kappa_{t}^{B} B_{i, t-1}+\kappa_{t} L_{i, t}-\right.$ $\left.R_{t}^{m} I_{i, t} \geq 0\right)$, and $\psi_{i, t}$ the multiplier on the goods market constraint. Further, the following first order conditions for holdings of bonds, money, and contingent claims

$$
\begin{aligned}
\lambda_{i, t} & =\beta R_{t} E_{t} \frac{\lambda_{i, t+1}+\kappa_{t+1}^{B} \eta_{i, t+1}}{\pi_{t+1}}, \\
\lambda_{i, t} & =\beta E_{t} \frac{\lambda_{i, t+1}+\psi_{i, t+1}}{\pi_{t+1}}, \\
q_{t, t+1} & =\frac{\beta}{\pi_{t+1}} \frac{\lambda_{i, t+1}}{\lambda_{i, t}},
\end{aligned}
$$

the associated complementary slackness conditions and the transversality conditions for money, bonds, and household debt hold. The debt rate is defined as follows

$$
R_{t}^{D}=1 / E_{t} q_{t, t+1}
$$

Combining the optimality conditions (14), (16), and (17) to

$$
R_{t} E_{t}\left[\left(\lambda_{i, t+1}+\kappa_{t+1}^{B} \eta_{i, t+1}\right) / \pi_{t+1}\right]=E_{t}\left[R_{t+1}^{m}\left(\lambda_{i, t+1}+\eta_{i, t+1}\right) / \pi_{t+1}\right]
$$

shows that households are indifferent between investing in money and investing in government bonds and converting these into cash in the next period at the rate $R_{t+1}^{m}$. When the open market constraint (2) is binding, $\eta_{t}>0$, the interest rate on government bonds $R_{t}$ depends on $\kappa^{B}$. For $\kappa_{t}^{B}=1$, it equals the next period's expected policy rate up to first order.

money from the private sector $I_{i, t} \geq 0$. 
When government bonds are less liquid $\left(\kappa_{t}^{B}<1\right)$, households demand a higher bond rate $R_{t}$. Likewise, condition (15) shows that the loan rate $R_{t}^{L}$ depends on the fraction of loans eligible as collateral in open market operations, $\kappa_{t}$. When loans are not eligible $\kappa_{t}=0$, there can be a spread between the policy rate and the loan rate, i.e. a liquidity premium, while for $\kappa_{t}=1$ the loan rate equals the policy rate, $R_{t}^{L}=R_{t}^{m}$.

\subsection{Public sector}

The central bank transfers seigniorage revenues $P_{t} \tau_{t}^{m}$ to the Treasury, which issues oneperiod bonds and pays a wage subsidy at a constant rate $\tau^{n}$. The supply of short-term government bonds is modelled in simple way. We assume that the total amount of shortterm government bonds $B_{t}^{T}$, which will either be held by households or the central bank, grows a the constant rate $\Gamma$,

$$
B_{t}^{T}=\Gamma B_{t-1}^{T}, \quad \Gamma>0
$$

given $B_{-1}^{T}>0$. Note that we do not aim to measure total public debt by the stock of shortterm bonds $B_{t}^{T}$. It rather summarizes a subset of public debt instruments that are eligible for open market operations. To avoid further effects of fiscal policy, we assume that the government has access to lump-sum transfers $P_{t} \tau_{t}$, which adjust to balance the budget. ${ }^{15}$ The treasury's budget constraint reads

$$
\left(B_{t}^{T} / R_{t}\right)+P_{t} \tau_{t}^{m}=B_{t-1}^{T}+P_{t} \tau_{t}+\tau^{n} P_{t} w_{t} n_{t}
$$

The central bank can supply money against loans under repos, $M_{t}^{L}=\int_{0}^{1} M_{i, t}^{L} d i$, or against government bonds in open market operations. Money supplied in exchange for the latter can either be issued under repos, $M_{t}^{R}=\int_{0}^{1} M_{i, t}^{R} d i$, or outright, $M_{t}^{H}=\int_{0}^{1} M_{i, t}^{H} d i$, such that its budget constraint reads

$$
\left(B_{t}^{c} / R_{t}\right)-B_{t-1}^{c}+P_{t} \tau_{t}^{m}=R_{t}^{m}\left(M_{t}^{H}-M_{t-1}^{H}\right)+\left(R_{t}^{m}-1\right)\left(M_{t}^{R}+M_{t}^{L}\right)
$$

where $B_{t}^{c}$ denotes bonds held by the central bank. It transfers earnings on investments in government bonds and from repos to the treasury at end of period, $P_{t} \tau_{t}^{m}=B_{t}^{c}\left(1-1 / R_{t}\right)+$

\footnotetext{
${ }^{15}$ Introducing long-term illiquid government bonds as an additional means of financing government expenditures would therefore not have any effects.
} 
$\left(R_{t}^{m}-1\right)\left(M_{t}^{R}+M_{t}^{L}\right)$. Substituting out transfers in (23) shows that the bond holdings of the central bank evolve according to

$$
B_{t}^{c}-B_{t-1}^{c}=R_{t}^{m}\left(M_{t}^{H}-M_{t-1}^{H}\right)
$$

The central bank has three main instruments. First, it conducts interest rate policy, i.e. it sets the policy rate $R_{t}^{m}$. We will refer to its long-run value $R^{m}$ as the policy rate target. Second, it can change its money supply policy, i.e. it decides on how many assets to accept in open market operations, which requires controlling both, $\kappa_{t} L_{t}$ and $\kappa_{t}^{B} B_{t-1}$. Third, it can alter the collateral standards by raising (or lowering) the fraction of eligible loans relative to the total amount of accepted assets, $\kappa_{t} L_{t} /\left(\kappa_{t} L_{t}+\kappa_{t}^{B} B_{t-1}\right)$. Concisely, using the latter two instruments requires adjusting $\kappa_{t}$ and $\kappa_{t}^{B}$ in a state contingent way.

Finally, it can decide whether money is supplied in exchange for government bonds via repos or outright (while loans are only traded under repos). We assume that it sets the ratio of treasury repos to outright sales of bonds $\Omega_{t}>0: M_{t}^{R}=\Omega_{t} M_{t}^{H}$, which will only be relevant for the implementation of the long-run inflation target (see section 3 ).

\subsection{Equilibrium}

In equilibrium, there will be no arbitrage opportunities and markets clear, $n_{t}=\int_{0}^{1} n_{j t} d j=$ $\int_{0}^{1} n_{i t} d i, y_{t}=\int_{0}^{1} y_{k t} d j=\int_{0}^{1} c_{i t} d i=c_{t}$, and $\int_{0}^{1} L_{i, t} d i=\int_{0}^{1} L_{j, t} d j=L_{t}$. Households will behave in an identical way and aggregate stocks of asset satisfy $\forall t \geq 0: \int_{0}^{1} D_{i, t} d i=0$, $\int_{0}^{1} M_{i, t}^{H} d i=\int_{0}^{1} \widetilde{M}_{i, t} d i=M_{t}^{H}, \int_{0}^{1} M_{i, t}^{R} d i=M_{t}^{R}, \int_{0}^{1} M_{i, t}^{L} d i=M_{t}^{L}=\kappa_{t} L_{t} / R_{t}^{m}, \int_{0}^{1} B_{i, t} d i=B_{t}$, $\int_{0}^{1} B_{i, t}^{c} d i=B_{t}^{c}, \int_{0}^{1} I_{i, t} d i=I_{t}=M_{t}^{H}-M_{t-1}^{H}+M_{t}^{R}+M_{t}^{L}, M_{t}^{H}-M_{t-1}^{H}+M_{t}^{R}=\kappa_{t}^{B} B_{t} / R_{t}^{m}$, and $B_{t}^{T}=B_{t}+B_{t}^{c}$. Households' real bond holdings evolve according to (see 21 and 24)

$$
b_{t}-b_{t-1} \pi_{t}^{-1}=(\Gamma-1) b_{t-1}^{T} \pi_{t}^{-1}-R_{t}^{m}\left(m_{t}^{H}-m_{t-1}^{H} \pi_{t}^{-1}\right) .
$$

Since intermediate goods producing firms behave in an identical way, their aggregate output satisfies $I O_{t}=a_{t} n_{t}^{\alpha}$. Retailers can differ with regard to their prices, which might lead to a dispersion of retail prices. Market clearing for the intermediate goods market, $I O_{t}=$ $\int_{0}^{1} y_{k, t} d k$ then implies for aggregate output $a_{t} n_{t}^{\alpha}=\int_{0}^{1}\left(P_{k, t} / P_{t}\right)^{-\varepsilon} y_{t} d k \Leftrightarrow$

$$
y_{t}=a_{t} n_{t}^{\alpha} / s_{t}
$$


where $s_{t}$ is a measure for price dispersion, $s_{t}=\int_{0}^{1}\left(P_{k, t} / P_{t}\right)^{-\varepsilon} d k$ and evolves according to $s_{t}=(1-\phi) \tilde{Z}_{t}^{-\varepsilon}+\phi s_{t-1} \pi_{t}^{\varepsilon}$ (see e.g. Schmitt-Grohé and Uribe, 2006) given $s_{-1}=1$. A rational expectations (RE) equilibrium is defined as follows (see also appendix $\mathrm{A}$ ):

Definition $1 A R E$ equilibrium is a set of sequences $\left\{c_{t}, n_{t}, y_{t}, \lambda_{t}, \psi_{t}, \eta_{t}, m_{t}^{R}, m_{t}^{H}\right.$, $\left.b_{t}, b_{t}^{T}, l_{t}, w_{t}, m c_{t}, \tilde{Z}_{t}, Z_{t}^{1}, Z_{t}^{2}, s_{t}, \pi_{t}, q_{t, t+1}, R_{t}, R_{t}^{D}, R_{t}^{L}\right\}_{t=0}^{\infty}$ satisfying $m c_{t} a_{t} \alpha n_{t}^{\alpha-1}=$ $\left(1-\tau^{n}\right) w_{t} R_{t}^{L}, l_{t} / R_{t}^{L}=w_{t} n_{t}$, (12)-(19) where $x_{i, t}=x_{t} \forall x_{i, t} \in\left\{n_{i, t}, c_{i, t}, \lambda_{i, t}, \psi_{i, t}, \eta_{i, t}\right\}, c_{t}=$ $m_{t}^{H}+m_{t}^{R}+\kappa_{t} l_{t} / R_{t}^{m}$ if $\psi_{t}>0$ or $c_{t} \leq m_{t}^{H}+m_{t}^{R}+\kappa_{t} l_{t} / R_{t}^{m}$ if $\psi_{t}=0, \kappa_{t}^{B} b_{t-1} /\left(R_{t}^{m} \pi_{t}\right)=m_{t}^{H}-$ $m_{t-1}^{H} \pi_{t}^{-1}+m_{t}^{R}$ if $\eta_{t}>0$ or $\kappa_{t}^{B} b_{t-1} /\left(R_{t}^{m} \pi_{t}\right) \geq m_{t}^{H}-m_{t-1}^{H} \pi_{t}^{-1}+m_{t}^{R}$ if $\eta_{t}=0, \tilde{Z}_{t}=\frac{\varepsilon}{\varepsilon-1} Z_{t}^{1} / Z_{t}^{2}$, $Z_{t}^{1}=c_{t}^{-\sigma} y_{t} m c_{t}+\phi \beta E_{t} \pi_{t+1}^{\varepsilon} Z_{t+1}^{1}, Z_{t}^{2}=c_{t}^{-\sigma} y_{t}+\phi \beta E_{t} \pi_{t+1}^{\varepsilon-1} Z_{t+1}^{2}, 1=(1-\phi)\left(\tilde{Z}_{t}\right)^{1-\varepsilon}+\phi \pi_{t}^{\varepsilon-1}$, $s_{t}=(1-\phi) \tilde{Z}_{t}^{-\varepsilon}+\phi s_{t-1} \pi_{t}^{\varepsilon}, m_{t}^{R}=\Omega_{t} m_{t}^{H}, b_{t}^{T}=\Gamma b_{t-1}^{T} / \pi_{t}$, (25), (26), $y_{t}=c_{t}$, the transversality conditions, a monetary policy setting $\left\{R_{t}^{m} \geq 1, \kappa_{t}^{B}, \kappa_{t} \in[0,1]\right\}_{t=0}^{\infty}, \Omega_{t}>0$, and $\pi \geq \beta, a$ subsidy $\tau^{n}$, for given sequences $\left\{a_{t}, \mu_{t}\right\}_{t=0}^{\infty}$ and initial values $M_{-1}^{H}, B_{-1}, B_{-1}^{T}$, and $s_{-1}=1$.

Definition 1 accounts for both cases where the goods market constraint and the open market constraint are binding and non-binding. Throughout the analysis, we are particularly interested in the case where the open market constraint is binding. We will show that the central bank can then apply its instruments in a way that enhances welfare beyond pure interest rate policy. If, however, the open market constraint is not binding, the model reduces to a conventional sticky price model with transactions frictions (see definition 2 in appendix A). The households' optimal consumption and labor supply decisions are then not affected by money rationing, like in standard New Keynesian models with lump-sum money supply. ${ }^{16}$

Corollary 1 For given sequences $\left\{w_{t}, \pi_{t}, \mu_{t}\right\}_{t=0}^{\infty}$ and a monetary policy $\left\{R_{t}^{m} \geq 1\right\}_{t=0}^{\infty}$, consumption and working time $\left\{c_{t}, n_{t}\right\}_{t=0}^{\infty}$ are determined by $c_{t}^{-\sigma}=\beta R_{t}^{m} E_{t}\left[c_{t+1}^{-\sigma} \pi_{t+1}^{-1}\right]$ and $\mu_{t} \chi n_{t}^{\eta}=$ $w_{t} c_{t}^{-\sigma}$, if the open market constraint is not binding, $\eta_{t}=0$. The equilibrium loan rate then satisfies $R_{t}^{L}=R_{t}^{m}$.

For $\eta_{t}=0$, the policy rate will affect consumption growth via a standard Euler equation (see Clarida et al., 1999). In case of a binding open market constraint, $\eta_{t}>0$, this will not be the case, since the consumption Euler rate and the policy rate will differ by a liquidity premium. Consumption growth will then not depend on the policy rate in the way summarized in corollary 1, while money and therefore consumption will be rationed by the amount of eligible collateral. The central bank can then affect the private sector behavior by changing the terms of lending and by setting the policy rate.

\footnotetext{
${ }^{16} \mathrm{~A} \log$-linearly approximated version of the model can then be reduced to a set of three equations (see appendix A).
} 
In the subsequent sections, we will repeatedly refer to the first best allocation, which solves $\max E \sum_{i} \sum_{t=0}^{\infty} \beta^{t} u\left(c_{i, t}, n_{i, t}\right)$, s.t. $\int_{0}^{1} y_{k, t} d k=a_{t}\left(\int_{0}^{1} n_{i t} d i\right)^{\alpha}$ and $\left(\int_{0}^{1} c_{i t} d i\right)^{\frac{\varepsilon-1}{\varepsilon}}=\int_{0}^{1} y_{k t}^{\frac{\varepsilon-1}{\varepsilon}} d k$. It can easily be shown that the solution satisfies $a_{t} \alpha n_{t}^{\alpha-1}=\chi n_{t}^{\eta} c_{t}^{\sigma}$ and $c_{t}=a_{t} n_{t}^{\alpha}$. The first best allocation is characterized by the following corollary.

Corollary 2 The first best allocation satisfies $a_{t} \alpha n_{t}^{\alpha-1}=\chi n_{t}^{\eta} c_{t}^{\sigma}$ and $c_{t}=a_{t} n_{t}^{\alpha} \forall t \geq 0$, and is given by

$$
n_{t}^{*}=n^{*} a_{t}^{\frac{1-\sigma}{\eta+\alpha \sigma+1-\alpha}} \text { and } c_{t}^{*}=c^{*} a_{t}^{\frac{1+\eta}{\eta+\alpha \sigma+1-\alpha}} \text {, where } n^{*}=(\alpha / \chi)^{\frac{1}{\eta+\alpha \sigma+1-\alpha}} \text { and } c^{*}=\left(n^{*}\right)^{\alpha} .
$$

It will be shown that monetary policy - together with the wage subsidy - can implement first-best (27) by setting its targets and its instruments in a way that eliminates distortions induced by the transactions friction, the cost push shocks, and imperfectly flexible prices.

\section{$3 \quad$ Long-run effects of monetary policy}

In this section, we examine the long-run effects of monetary policy. Before we identify the long-run optimal policy, we summarize main steady state properties, where constant steady state values of endogenous variables will not be indexed with a time index. Further details on the steady state can be found in appendix B. Following the New Keynesian literature on optimal monetary policy (Woodford, 2003), we assume that the wage subsidy eliminates the long-run distortions due to average mark-ups:

$$
\tau^{n}=1-[(\zeta-1) / \zeta][(\varepsilon-1) / \varepsilon]
$$

Even though average mark-ups are eliminated by the subsidy, the steady state allocation can still deviate from first-best (see corollary 2), due to i.) long-run price instability, which is associated with price dispersion and an inefficient allocation of working time (see 26), and ii.) positive costs of liquidity required by firms to meet the working capital constraint (1).

Consider the case where all government bonds are eligible, $\kappa_{t}^{B}=1$, while loans (and private debt) are not accepted in open market operations. In the steady state, the debt rate $R^{D}$ satisfies $R^{D}=\pi / \beta$ (see 18 ). In contrast to standard models, where the debt rate (i.e. the Euler rate) is assumed to equal the policy rate, the central bank can set the policy rate target $R^{m}$ at a value lower than $\pi / \beta$, such that $R^{m}<R^{D}$. Households will only invest in bonds if the return is not smaller than the rate $R^{m}$, at which they can exchange 
bonds against money. Hence, in an arbitrage-free long-run equilibrium the interest rate on government bonds equals the policy rate, $R=R^{m}$ (see 20).

When the policy rate target satisfies $1 \leq R^{m}<R^{D}$, the open market constraint (2) will be binding in the steady state. The reason is that households economize on bond holdings when interest rate earnings from government bonds $R$ are smaller than on household debt $R^{D}$, while they can use bonds for open market operations. Further, the goods market constraint (3) will be binding in a steady state, if the inflation target exceeds $\beta$, such that $R^{D}=\pi / \beta>1$. Then, households can earn interest by investing in private debt, such that they economize on money holdings and use money only for goods market expenditures. Notably, this result holds regardless of the policy rate and even if it is set at its zero lower bound, $R^{m}=1$. These results for the case where only treasury debt is eligible ("Treasuries only") are summarized in the following proposition.

Proposition 1 Suppose that government bonds are eligible, but not loans, $\kappa_{t}^{B} \in(0,1]$ and $\kappa_{t}=0$. In the steady state, interest rates are then characterized by $R^{D}=R^{L}=\pi / \beta$ and $R \in\left[R^{m}, R^{D}\right)$, the goods market constraint is binding for an inflation target satisfying $\pi>\beta$, and the open market constraint is binding for a policy rate satisfying $R^{m} \in[1, \pi / \beta)$.

Proof. See appendix B.

When the open market constraint (2) is binding, access to money is restricted by the amount of collateral. Thus, the supply of short-term government bonds might be relevant for the equilibrium allocation and the associated price level. The central bank can nevertheless implement its inflation target independent from the supply of government bonds by using its instruments. In particular, it can implement long-run price stability regardless whether the total amount of government bonds grows $(\Gamma>1)$ or shrinks $(\Gamma<1)$ by adjusting the fraction of eligible government bonds $\kappa_{t}^{B}$ or the share of money supplied outright $1 /\left(1+\Omega_{t}\right) \leq 1$ in a way described in the following proposition.

Proposition 2 For a policy rate target satisfying $R^{m} \in[1, \pi / \beta)$, the central bank can implement long-run price stability $\pi=1$ for $\Gamma \geq 1$ if it sets the fraction of eligible bonds $\kappa_{t}^{B}$ according to $\kappa_{t}^{B}=\Gamma^{-1} \kappa_{t-1}^{B}$, and for $\Gamma<1$ if it sets $\kappa_{t}^{B}=\kappa^{B}<1$ and the share of money supplied outright $\left(1+\Omega_{t}\right)^{-1}$ according to $\left(1+\Omega_{t}\right)^{-1}=\Gamma\left(1+\Omega_{t-1}\right)^{-1}$.

Proof. See appendix B. 
If, for example, government bonds grow at a positive rate $\Gamma>1$, long-run price stability requires the fraction of eligible bonds $\kappa_{t}^{B}$ to shrink with the rate $\Gamma$, such that increasingly less money can be obtained per bond. If total government bonds shrink over time, $\Gamma<1$, then this instrument is not applicable due to its upper bound, $\kappa_{t}^{B} \leq 1$. In this case, the central bank can adjust the share of money supplied outright $1 /\left(1+\Omega_{t}\right)$ at the rate $\Gamma$ such that it increasingly supplies money under repos. It should be noted that the results presented in proposition 2 do not rely on any further restriction on the share of eligible loans $\kappa$. The reason is that the firms' demand for loans is bounded by the nominal wage bill, which in the long-run cannot grow independently from the aggregate price level.

We now examine optimal long-run monetary policy, for which we consider the case where the central bank accepts loans in exchange for money in open market operations. The steady state allocation is then affected by the collateral standards in open market operations, i.e. by the share of loans eligible in open market operations $\kappa$. The reason is that the loan rate raises the firms' borrowing costs, while the level of the loan rate is affected by the central bank's choice for $\kappa$ :

$$
R^{L}=\left[\kappa\left(1 / R^{m}\right)+(1-\kappa)\left(1 / R^{D}\right)\right]^{-1},
$$

(see appendix $\mathrm{B}$ for the derivation). As long as loans are not eligible, $\kappa=0$, the loan rate equals the debt rate $R^{L}=R^{D}$ (see proposition 1). Under a binding open market constraint, $R^{m}<R^{D}$, this result does not hold if $\kappa>0$. By increasing the fraction of eligible loans $\kappa$ (for a given policy rate) or by lowering the policy rate (for a given $\kappa>0$ ), the central bank can induce a lower steady state loan rate. Condition (29) further reveals that $R^{L}=1$, if $R^{m}=1$ and $\kappa=1$. To see how this affects the allocation, consider that the equilibrium allocation satisfies $\mu_{t} \chi n_{t}^{\eta}=w_{t} c_{t}^{-\sigma}$ (see definition 1). Substituting out wages with (6) and working time with (26), leads to the following condition for steady state consumption

$$
c=\left[(\alpha / \chi)\left(m c \cdot s^{\sigma} / R^{L}\right)\right]^{\alpha /(\eta+\alpha \sigma+1-\alpha)} s^{-1}
$$

while the first-best steady state consumption level is given $c^{*}=(\alpha / \chi)^{\alpha /(\eta+\alpha \sigma+1-\alpha)}$ (see 27). Given that fiscal transfers eliminate the average mark-up distortion, the marginal cost of final goods producing firms and the dispersion term equal one in steady state if prices are stable: $\pi=1 \Rightarrow m c=s=1$ (see appendix B for further details). Condition (30) shows 
that long-run consumption can further deviate from its first-best level, if the loan rate is positive. However, the central bank can implement the long-run first best allocation $\left(c^{*}, n^{*}\right)$ by setting its targets and instruments as follows.

Proposition 3 The long-run efficient allocation can be implemented by the central bank if and only if it accepts all loans as collateral and sets both targets equal to one,

$$
\kappa=1, R^{m}=1 \text {, and } \pi=1 \text {. }
$$

Proof. See appendix B.

The distortions due to price dispersion and due to the liquidity constraint (1) cannot be eliminated simultaneously, if money supply is not effectively rationed (see corollary 1), or if the central bank supplies money in a lump-sum way like in standard models. Then, there exists no liquidity premium on eligible assets and the policy rate equals the loan rate (and the debt rate). Thus, the Fisher equation applies for the policy rate $\left(R^{m}=\pi / \beta\right)$ in a long-run equilibrium, implying that the policy rate and the inflation rate cannot both be set equal to one. Put differently, the long-run efficient allocation cannot be implemented if the policy rate $R^{m}$ is set equal to the long-run Euler rate $R^{D}$.

If however the central bank sets its policy rate target $R^{m}<\pi / \beta$, such that open market constraint is binding, it can eliminate the distortion due to price dispersion by setting the inflation target equal to one $(\pi=1)$ and the distortion due to the liquidity constraint by setting the policy rate and the share of eligible loans equal to one (see proposition 3), implying zero cost of borrowing $\left(R^{L}=1\right)$.

\section{Optimal stabilization policy}

In the previous section, we have shown how the central bank can implement an efficient long-run allocation. In this section, we turn to the task of optimal stabilization in face of aggregate shocks, i.e., productivity and mark-up shocks. Throughout this section, we will restrict our attention to the case where the central bank targets are set in accordance with long-run efficiency, $R^{m} \in[1, \pi / \beta)$ and $\pi>\beta$, which ensures that the goods market constraint and the open market constraint bind in the neighborhood of the steady state (see proposition 1). We then assume that the economy is initially in the steady state and that disturbances are sufficiently small such that it stays in its neighborhood. Since we aim at 
providing an answer to the question if monetary policy is in principle able to implement first-best, we disregard issues related to the time inconsistency of optimal policy. ${ }^{17}$

\subsection{Perfectly flexible prices}

Before we turn to the more realistic case of imperfectly flexible prices, we examine optimal policy under perfectly flexible prices. In order to isolate welfare gains from short-run stabilization, we will assume that the fixed wage subsidy $\tau^{n}$ eliminates long-run distortions, which originate in the average mark-ups and in the long-run costs of borrowing. Instead of (28), we will therefore assume that the subsidy is now given by $\tau^{n}=1-\frac{\zeta-1}{\zeta} \frac{\varepsilon-1}{\varepsilon} / R^{L}$, like in Ravenna and Walsh (2004), who also examine optimal monetary stabilization in a sticky price model where firms face a working capital constraint.

Using definition 1, we can redefine a RE equilibrium allocation under binding goods and open market constraints, perfectly flexible prices $(\phi=0)$, and a subsidy $\tau^{n}=1-$ $[(\zeta-1) / \zeta][(\varepsilon-1) / \varepsilon] / R^{L}$ as a set of sequences $\left\{c_{t}, n_{t}, \pi_{t}, w_{t}, m_{t}^{H}, R_{t}^{L}, b_{t}, b_{t}^{T}\right\}_{t=0}^{\infty}$ satisfying

$$
\begin{aligned}
a_{t} \alpha n_{t}^{\alpha-1} & =\chi n_{t}^{\eta} c_{t}^{\sigma}\left(\mu_{t} / \mu\right)\left(R_{t}^{L} / R^{L}\right), \\
c_{t} & =a_{t} n_{t}^{\alpha} \\
R_{t}^{L} & =\left\{\left(1-\kappa_{t}\right) \beta E_{t}\left[\left(c_{t+1}^{-\sigma} / c_{t}^{-\sigma}\right) \pi_{t+1}^{-1}\right]+\kappa_{t} / R_{t}^{m}\right\}^{-1}, \\
w_{t} & =\mu_{t} \chi n_{t}^{\eta} c_{t}^{\sigma}, \\
c_{t} & =\left(1+\Omega_{t}\right) m_{t}^{H}+\kappa_{t}\left(w_{t} n_{t} R_{t}^{L} / R_{t}^{m}\right), \\
\kappa_{t}^{B} b_{t-1} \pi_{t}^{-1} & =R_{t}^{m}\left[\left(1+\Omega_{t}\right) m_{t}^{H}-m_{t-1}^{H} \pi_{t}^{-1}\right], \\
b_{t}-b_{t-1} \pi_{t}^{-1} & =(\Gamma-1) b_{t-1}^{T} \pi_{t}^{-1}-R_{t}^{m}\left(m_{t}^{H}-m_{t-1}^{H} \pi_{t}^{-1}\right), \\
b_{t}^{T} & =\Gamma b_{t-1}^{T} / \pi_{t},
\end{aligned}
$$

and the transversality conditions, for given sequences of monetary policy instruments $\left\{R_{t}^{m} \geq\right.$ $\left.\left.1, \kappa_{t}^{B}, \kappa_{t} \in[0,1]\right\}_{t=0}^{\infty}, \Omega_{t}>0\right\}_{t=0}^{\infty}$ and targets $R^{m} \in[1, \pi / \beta)$ and $\pi>\beta$, sequences of stochastic variables $\left\{a_{t}, \mu_{t}\right\}_{t=0}^{\infty}$ and initial values $M_{-1}^{H}>0, B_{-1}>0$, and $B_{-1}^{T}>0$.

Under flexible prices the central bank can easily implement the first best allocation of consumption and working time, as given in corollary 2. Comparing (27) with (32) and (33)

\footnotetext{
${ }^{17}$ The optimality conditions that will be presented in this section can be interpreted as being part of a commitment plan derived and implemented in a timeless perspective (see Woodford, 2003).
} 
immediately shows that the first best allocation $\left\{c_{t}^{*}, n_{t}^{*}\right\}_{t=0}^{\infty}$ can be implemented if the loan rate off-sets mark-up shocks, $\left(\mu_{t} / \mu\right)\left(R_{t}^{L} / R^{L}\right)=1$. Substituting out the loan rate with (34) this condition can be rewritten as

$$
\left(\kappa_{t} / R_{t}^{m}\right)+\left(1-\kappa_{t}\right) \beta E_{t}\left(c_{t+1} / c_{t}\right)^{-\sigma} \pi_{t+1}^{-1}=\mu_{t} /\left(\mu R^{L}\right)
$$

Condition (40) can be satisfied only if the policy rate or the expected inflation rate are functions of the mark-up shock, since consumption is then given by $c_{t}=c_{t}^{*}$ and thus a function of the productivity shock, but not of the mark-up shock (see 27). In the case where loans are not eligible $\kappa_{t}=0$, the policy rate $R_{t}^{m}$ does not directly affect the loan rate. Then, implementation of the first best allocation requires expected inflation to be a function of today's mark-up shocks. For this, the central bank can use its instruments $\left(R_{t}^{m}, \kappa_{t}\right.$, and $\left.\kappa_{t}^{B}\right)$ to manipulate the inflation rate via (37) as described in the following proposition.

Proposition 4 When prices are perfectly flexible, $\phi=0$, the central bank implements the first best allocation $\left\{c_{t}^{*}, n_{t}^{*}\right\}_{t=0}^{\infty}$ if it sets $R_{t}^{m}, \kappa_{t}$, and $\kappa_{t}^{B} \forall t \geq 0$ according to

$$
\frac{\kappa_{t}}{R_{t}^{m}}+\frac{1-\kappa_{t}}{1 / \beta} E_{t}\left[\left(\frac{c_{t}}{c_{t+1}}\right)^{\sigma-1} \frac{\left(1-\kappa_{t} \alpha \mu R^{L} / R_{t+1}^{m}\right)}{\kappa_{t+1}^{B} b_{t}\left(c_{t} R_{t+1}^{m}\right)^{-1}+\left(1-\kappa_{t} \alpha \mu R^{L} / R_{t}^{m}\right) /\left(1+\Omega_{t}\right)}\right]=\frac{\mu_{t}}{\mu R^{L}} .
$$

for any $\Omega_{t}>0$. Then, there exists a unique associated price level sequence $\left\{P_{t}\right\}_{t=0}^{\infty}$.

\section{Proof. See appendix C.}

In contrast to productivity shocks, the wage mark-up shock is distortionary and should be eliminated by off-setting adjustments of central bank instruments. Since there are three instruments available, there exist infinitely many sets of sequences for the instruments that implement the first best allocation. For example, if the central bank accepts no loans in open market operations, $\kappa_{t}=0$, and holds the fraction of eligible bonds constant, $\kappa_{t}^{B}=\kappa^{B}>0$, it can set the future policy rate rate $R_{t+1}^{m}$ in a predetermined way, i.e. contingent on information in period $t, R_{t+1}^{m}=\left[\kappa^{B} b_{t} / c^{*}\left(a_{t}\right)\right]\left\{\left(\mu R^{L} / \mu_{t}\right) \beta E_{t}\left[\left(c^{*}\left(a_{t}\right) / c^{*}\left(a_{t+1}\right)\right)^{\sigma-1}\right]-1 /(1+\Omega)\right\}^{-1}$, to satisfy (41). If it pegs the policy rate, $R_{t}^{m}=R^{m}>0$, and accepts a constant fraction of loans, $\kappa_{t}=\kappa>0$, then it can still adjust $\kappa_{t}^{B}$ for a given stock of real bonds to ensure that (41) holds. ${ }^{18}$ The easiest way to implement the first best allocation is to accept all loans

\footnotetext{
${ }^{18}$ Precisely, $\kappa_{t+1}^{B}$ has to be adjusted in the following backward-looking way to satisfy (41): $\kappa_{t+1}^{B} b_{t}=$
} 
as collateral in open market operations, $\kappa_{t}=1$, such that the loan rate is identical to the policy rate $R_{t}^{L}=R_{t}^{m}$ (see 34 ). Then, the central bank can directly control the loan rate in a way that off-sets changes in the wage mark-up, $R_{t}^{m} / R^{m}=\mu / \mu_{t}$. In any case, the price level sequence is uniquely determined under (41), while price level trends can be avoided by long-run adjustments of $\kappa_{t}^{B}$ or $\Omega_{t}$ (see proposition 2).

If, however, one assumes that the policy rate target is set to equal the long-run debt rate $R^{m}=R^{d}=\pi / \beta$, like in standard New Keynesian models, then the open market constraint is not binding (see proposition 1). For this case, corollary 1 and (32)-(33) then imply that the equilibrium allocation $\left\{c_{t}, n_{t}\right\}_{t=0}^{\infty}$ satisfies $a_{t} \alpha n_{t}^{\alpha-1}=\chi n_{t}^{\eta} c_{t}^{\sigma}\left(\mu_{t} / \mu\right)\left(R_{t}^{m} / R^{m}\right)$ and $c_{t}=a_{t} n_{t}^{\alpha}$. Then, central bank can simply set its single instruments $R_{t}^{m}$ according to $R_{t}^{m} / R^{m}=\mu / \mu_{t}$ to implement first-best (as in the case of $\kappa_{t}=1$ ). In contrast to the case where money is rationed, the well-known price level indeterminacy problem then arises, i.e. there exist multiple price level sequences consistent with the equilibrium allocation.

To summarize, collateralized central bank lending and the associated instruments are under fully flexible prices relevant for price level determination, but are irrelevant for optimal stabilization. In the next subsection, it will be shown that the latter result will not hold for the empirically relevant case where prices are imperfectly flexible.

\subsection{Imperfectly flexible prices}

According to the conventional view on monetary policy, central banks typically face a tradeoff (between price level stabilization and closing output-gaps) when sticky prices and costpush shocks are present, which renders the implementation of a first best allocation impossible (see Clarida et al., 1999, or Woodford, 2003). If, in contrast, only productivity shocks were present, the trade-off disappears. It is further known that the existence of transactions frictions can also lead to a trade-off, even if only productivity shocks are present (see Ravenna and Walsh, 2006, or Christiano et al. 2010). Thus, according to a standard monetary policy analysis, first-best can - even when long-run distortions are eliminated - not be implemented by the central bank if cost-push shocks or liquidity constraints exist. Here, we show that this result does not hold when the central bank applies additional instruments

$\frac{\left[\mu_{t} R^{m} /\left(\mu R^{L}\right)\right]-\kappa}{(1-\kappa)\left(1-\alpha \mu R^{L} \kappa / R^{m}\right)} \frac{c^{*}\left(z_{t}\right)^{-\sigma}}{\beta E_{t} c^{*}\left(z_{t+1}\right)^{1-\sigma}}-c^{*}\left(z_{t}\right) \frac{R^{m}-\alpha \mu R^{L} \kappa}{1+\Omega}$. 
available under collateralized lending.

Based on definition 1, we can redefine a RE equilibrium under binding goods and open market constraints, imperfectly flexible prices $(\phi>0)$, and a subsidy $\tau^{n}=1-$ $[(\zeta-1) / \zeta][(\varepsilon-1) / \varepsilon] / R^{L}$ as a set of sequences $\left\{m c_{t}, s_{t}, c_{t}, n_{t}, \pi_{t}, w_{t}, m_{t}^{H}, R_{t}^{L}, b_{t}, b_{t}^{T}\right\}_{t=0}^{\infty}$ satisfying (34)-(39),

$$
\begin{aligned}
m c_{t} a_{t} \alpha n_{t}^{\alpha-1} & =\chi n_{t}^{\eta} c_{t}^{\sigma}\left(\mu_{t} / \mu\right)\left(R_{t}^{L} / R^{L}\right), \\
c_{t} & =a_{t} n_{t}^{\alpha} / s_{t}, \\
s_{t}-\phi s_{t-1} \pi_{t}^{\varepsilon} & =(1-\phi)\left[\left(1-\phi \pi_{t}^{\varepsilon-1}\right) /(1-\phi)\right]^{-\varepsilon /(1-\varepsilon)}, \\
{\left[\left(1-\phi \pi_{t}^{\varepsilon-1}\right) /(1-\phi)\right]^{1 /(1-\varepsilon)} } & =\frac{E_{t} \sum_{s=0}^{\infty}(\phi \beta)^{s}\left(\prod_{k=1}^{s} \pi_{t+k}^{\varepsilon}\right) c_{t+s}{ }^{1-\sigma} m c_{t+s}}{E_{t} \sum_{s=0}^{\infty}(\phi \beta)^{s}\left(\Pi_{k=1}^{s} \pi_{t+k}^{\varepsilon-1}\right) c_{t+s}{ }^{1-\sigma}},
\end{aligned}
$$

and the transversality conditions, for given sequences of monetary policy instruments $\left\{R_{t}^{m} \geq\right.$ $\left.\left.1, \kappa_{t}^{B}, \kappa_{t} \in[0,1]\right\}_{t=0}^{\infty}, \Omega_{t}>0\right\}_{t=0}^{\infty}$ and targets $R^{m} \in[1, \pi / \beta)$ and $\pi>\beta$, sequences of stochastic variables $\left\{a_{t}, \mu_{t}\right\}_{t=0}^{\infty}$ and initial values $M_{-1}>0, B_{-1}>0, B_{-1}^{T}>0$, and $s_{-1}=1$.

When prices are imperfectly flexible, time varying marginal costs of retailers and price dispersion can affect the equilibrium allocation, as can be seen from $m c_{t}$ and $s_{t}$ entering (42) and (43). Since the first best allocation is characterized by $a_{t} \alpha n_{t}^{\alpha-1}=\chi n_{t}^{\eta} c_{t}^{\sigma}$ and $c_{t}=a_{t} n_{t}^{\alpha}$ (see corollary 2), the conditions (42) and (43) imply that $m c_{t}=\left(\mu_{t} / \mu\right)\left(R_{t}^{L} / R^{L}\right)$ and $s_{t}=1$ have to be satisfied for the sticky price allocation to be efficient. The absence of price dispersion $\left(s_{t}=1\right)$ further requires constant prices $\pi_{t}=1$ by $(44)$ given $s_{-1}=1$, which is only consistent with optimal price setting when marginal costs equal one (see 45). Hence, the first best allocation can be implemented by the central bank if and only if it sets its instruments such that

$$
m c_{t}=1 \quad \text { and } \quad R_{t}^{L} / R^{L}=\mu / \mu_{t}
$$

or, equivalently, such that $\pi_{t}=1$ and (40). Given that the goods market constraint and the open market constraints are binding (see 36 and 37), the central bank can set the fraction of eligible government bonds $\kappa_{t}^{B}$ in a state contingent way that implies a consumption level, which is consistent with $m c_{t}=1$ under sticky prices. In particular, the central bank has to adjust the amount of eligible bonds $\kappa_{t}^{B} b_{t-1}$ to control money supply according to (36) 
and (37) such that consumption equals $\widetilde{c}_{t}$ and - by (43) - working time $\widetilde{n}_{t}$, which for $R_{t}^{L} / R^{L}=\mu / \mu_{t}$ imply $m c_{t}=1$ by (42) and (43). It can easily be verified that $\widetilde{c}_{t}$ and $\widetilde{n}_{t}$ are given by

$$
\widetilde{c}_{t}=s_{t}^{(\alpha-\eta-1) /(\eta+\alpha \sigma+1-\alpha)} c_{t}^{*} \quad \text { and } \quad \widetilde{n}_{t}=s_{t}^{\sigma /(\eta+\alpha \sigma+1-\alpha)} n_{t}^{*}
$$

Once (40) and (46) hold, such that $m c_{t}=1$, retailers will not change their prices such that $\pi_{t}=1$ according to (45), implying that there will be no price dispersion, and $s_{t}=1$ according to (44) given $s_{-1}=1$. The equilibrium allocation under sticky prices is then identical to the first best allocation, $\widetilde{c}_{t}=c_{t}^{*}$ and $\widetilde{n}_{t}=n_{t}^{*}$ (see 46 ). The following proposition summarizes the requirements for optimal stabilization policy.

Proposition 5 When prices are imperfectly flexible, $\phi>0$, the central bank implements price stability, $\pi_{t}=1$, and the first best allocation $\left\{c_{t}^{*}, n_{t}^{*}\right\}_{t=0}^{\infty}$ if it sets $\kappa_{t}>0$, and $R_{t}^{m}$ and $\kappa_{t}^{B}$ according to (40) and

$$
\kappa_{t}^{B} b_{t-1}=R_{t}^{m} \pi_{t}\left[\widetilde{c}_{t}\left(1-\kappa_{t} s_{t} m c_{t} \mu_{t} \alpha R_{t}^{L} / R_{t}^{m}\right)-m_{t-1}^{H} \pi_{t}^{-1}\right] .
$$

For $\kappa_{t}=0$, the first best allocation cannot be implemented.

\section{Proof. See appendix C}

Optimal stabilization policy under sticky prices can thus implement the first best allocation by using all instruments $R_{t}^{m}, \kappa_{t}$, and $\kappa_{t}^{B}$. For this, it is necessary to accept at least some loans in open market operations, $\kappa_{t}>0$. The central bank can then alter the loan rate directly by changes in the policy rate to off-set mark-up shocks (see 40). This can be done in the simplest way when all loans are eligible such that (40) reduces to $R_{t}^{m} / R^{m}=\mu / \mu_{t}$. Condition (47) further reveals that accepting more loans (higher $\kappa$ ) must be neutralized by a smaller fraction of eligible bonds (lower $\kappa_{t}^{B}$ ) to guarantee implementation of first-best.

If, however, loans are not eligible, $\kappa_{t}=0$, the loan rate $R_{t}^{L}$ equals the debt (Euler) rate $R_{t}^{d}$, and is only affected by the policy rate through its equilibrium impact on consumption and inflation, i.e., by induced changes in the equilibrium Euler rate (see 40). In this case, the remaining instruments, namely, the policy rate $R_{t}^{m}$ and the amount of eligible bonds $\kappa_{t}^{B} b_{t-1}$, jointly affect the consumption level (see 47 ), but they cannot further be used to off-set mark-up shocks. Put differently, changes in the policy rate do not directly alter the loan rate and therefore the firms' marginal costs when $\kappa_{t}=0$, such that all central bank 
instruments (jointly) exert a direct impact on the demand side. Hence, for $\kappa_{t}=0$ the central bank instruments are not sufficient to implement first-best under sticky prices. This result relates to the well-known trade-off between price level stabilization and closing output-gaps faced by central banks conducting pure interest rate policy (see Clarida et al., 1999). In our framework, this case corresponds an interest rate target $R^{m}=R^{d}=\pi / \beta$, such that the open market constraint is not binding (see corollary 1 and proposition 1 ). The policy rate would then be the single monetary policy instrument, which cannot simultaneously off-set mark-up shocks and implement a consumption level consistent with constant prices.

Hence, deviating from "Treasuries-only", $\kappa_{t}>0$, is necessary for the implementation of first-best when prices are imperfectly flexible. Since there exist more than one friction, the central bank has to use all its instruments, which has not been necessary under flexible prices. Moreover, the inflation target has to equal one under sticky prices to avoid longrun welfare losses due to dispersed prices. As summarized in proposition 2, this long-run inflation target can be achieved by the central bank, if it adjusts the growth rate of $\kappa_{t}^{B}$ or $\left(1+\Omega_{t}\right)$ in a way that off-sets long-run trends in the supply of government bonds. ${ }^{19}$

\subsection{Comparison with pure interest rate policy}

To compare an optimal central bank lending regime with a conventional pure interest rate policy regime, we calibrate the model, using standard parameter values as far as possible. The parameter of the utility function equal $\sigma=2$ and $\eta=0$, the labor income share $\alpha=0.66$, the substitution elasticity for intermediate goods $\varepsilon=10$, steady state working time $n=0.33$, and the fraction of non-optimally price adjusting firms $\phi=0.7$. The productivity process satisfies $a_{t}=a_{t-1}^{\rho_{a}} \exp \left(\varepsilon_{t}^{a}\right)$, where we follow Schmitt-Grohé and Uribe (2006) and set $\rho_{a}=0.856$ and $s d\left(\varepsilon_{t}^{a}\right)=0.0064$. The substitution elasticity $\zeta_{t}$ evolves according to $\zeta_{t}=\zeta^{1-\rho_{\zeta}} \zeta_{t-1}^{\rho_{\zeta}} \exp \left(\varepsilon_{t}^{\zeta}\right)$, where $\zeta=10$ and the process of $\zeta_{t}$ is calibrated such that the wage markup $\zeta_{t} /\left(\zeta_{t}-1\right)$ matches Galí et al.'s (2007) estimates, i.e. $\operatorname{Var}\left(\zeta_{t} /\left(\zeta_{t}-1\right)\right)=0.054^{2}$ and $\rho_{\zeta}=0.95$. The spread between the policy rate $R^{m}$ and the debt rate $R^{D}=\pi / \beta$ (which equals the loan rate $R^{L}$ in a steady state with $\kappa=0$ ), i.e. the liquidity premium, is set

\footnotetext{
${ }^{19}$ In case of a permanently growing supply of bonds, $\Gamma>1$, which would increase household bond holdings by (38), the central bank has to permanently lower $\kappa_{t}^{B}$ accordingly to implement $\widetilde{c}_{t}$, as can be seen from $b_{t-1}^{-1}$ on the LHS of (47).
} 
equal to 13 basis points (in terms of quarterly rates), which accords to Longstaff et al.'s (2005) evidence on the non-default component of corporate bond spreads. ${ }^{20}$

The inflation target is set in accordance with price stability, $\pi=1$. The policy rate target $R^{m}$ is set equal to its 20-year average $R^{m}=1.0105$ (or $4.28 \%$ in annualized terms), which together with the liquidity premium - implies a discount factor of $\beta=\left(1.0105+13 \cdot 10^{-4}\right)^{-1}=$ 0.9883. We consider two monetary policy regimes, the optimal central bank lending regime (as characterized in proposition 5) and a conventional interest rate policy regime, at the same steady state. For the latter regime, we apply time-invariant collateral standards, $\kappa_{t}^{B}=1$ and $\kappa=0$, and an inertial reaction function

$$
R_{t}^{m}=\left(R_{t-1}^{m}\right)^{\rho} R_{m}^{1-\rho}\left(\pi_{t} / \pi\right)^{w_{\pi}(1-\rho)}\left(\left[y_{t} / a_{t}\right] /[y / a]\right)^{w_{y}(1-\rho)},
$$

which has been estimated for the US by Justiniano and Primiceri (2008) with $w_{\pi}=1.92$, $w_{y}=0.1$, and $\rho=0.8$. We assume that the supply of short-run government bonds is constant, i.e. $\Gamma=1$. This assumption is made for convenience only and allows to disregard long-run adjustments of the monetary policy instruments, in particular, of $\kappa_{t}^{B}$ and $\Omega_{t}$ (see proposition 2. Given that $\Gamma=1$ is consistent with the inflation target, we keep the share of repos $\Omega$ constant and set it equal to 1.5 , which is consistent with pre-crises supply of federal funds (see Reynard and Schabert, 2009). Finally, for both optimal central bank lending regimes, which differ by the fraction of eligible loans $(\kappa=0.5$ and $\kappa=0.75)$, we adjust the steady state fraction of eligible government bonds $\kappa^{B}$ to ensure a steady state, which is identical to the pure interest rate policy steady state. $^{21}$

We first consider productivity shocks. Figure 1 shows the impulse responses to a productivity shock under two optimal policy regimes with $\kappa=0.5$ (solid line) and with $\kappa=0.75$ (starred line) and under a pure interest rate policy regime (dashed line). Under an optimal policy regime, which implements first-best (see proposition 5), consumption increases on im-

\footnotetext{
${ }^{20}$ They find that $49 \%$ of the spread between $A A A$ corporate bonds and Treasury securities can be assigned to the non-default component, which is highly correlated to measures of market liquidity. Given that the average short-term spread for $A A A$ corporate bonds equals 104 basis points at annualized rates, we consider a liquidity premium of 13 basis points (in quarterly terms).

${ }^{21}$ To be more precise, the policy instruments $\kappa$ and $\kappa^{B}$ are in the steady state related to each other by (see 36 and 37), $\kappa^{B}=R^{m} b^{-1} \Omega(1+\Omega)^{-1} n^{\alpha}\left[1-\kappa \mu \alpha /\left(\kappa+(1-\kappa) R^{m} \beta\right)\right]$, which we apply to determine real bonds $b$ using the pure interest rate policy regime with $\kappa^{B}=1$ and $\kappa=0$.
} 

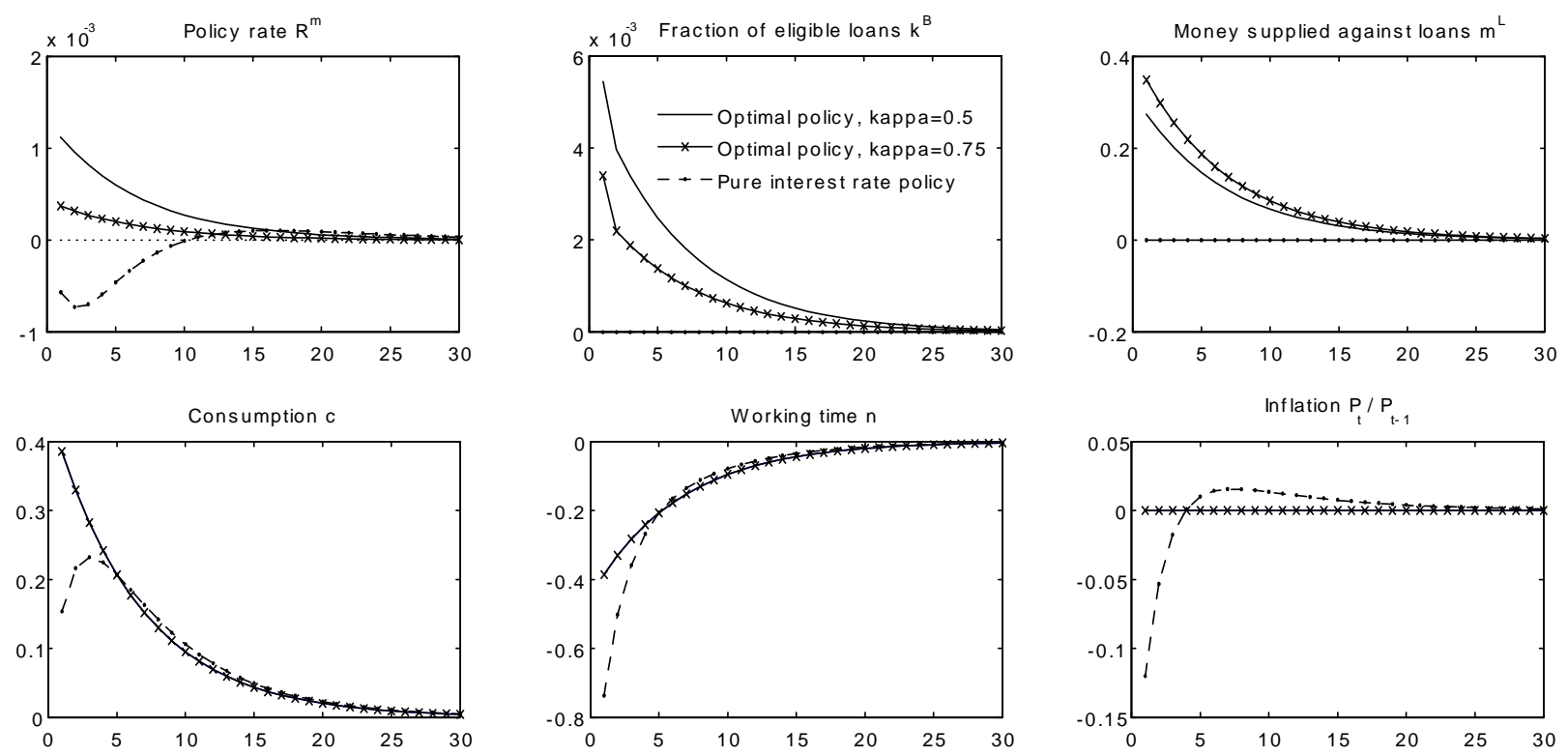

Figure 1: Responses to a one st. dev. productivity shock (in \% dev. from steady state, and $R$ and $\kappa^{B}$ in absolute dev.)

pact and working time falls, while prices are constant, which requires to keep marginal costs constant. Since firms' marginal costs are decreasing in productivity, this can be achieved via higher costs of borrowing. Hence, the central bank raises the policy rate, which tends to raise the loan rate by (40) for $\kappa>0$, while the increase in the policy rate is less pronounced for a higher share of accepted loans $(\kappa=0.75)$. The optimal consumption level is, at the same time, implemented by accommodating the productivity shock with an increase in the share of eligible bonds $\kappa_{t}^{B}$ and an increase in money supplied under repos against loans as collateral. In contrast, the central bank decreases the policy rate under a pure interest rate policy, which is modelled by the policy rule (48) and constant money supply instruments, $\kappa^{B}$ and $\kappa$. This policy cannot ensure price stability and is associated with a more pronounced decline in working time and a dampened consumption response compared to first-best. ${ }^{22}$

Figure 2 shows impulse responses to a wage mark-up shock. Under a pure interest rate policy (dashed line), which cannot stabilize prices and the allocation, the central bank slightly raises the policy rate, in accordance with the conventional monetary policy device

\footnotetext{
${ }^{22}$ The hump-shape of the impulse response function of consumption is mainly due to sluggish changes in the household real bond holdings that serve as collateral.
} 

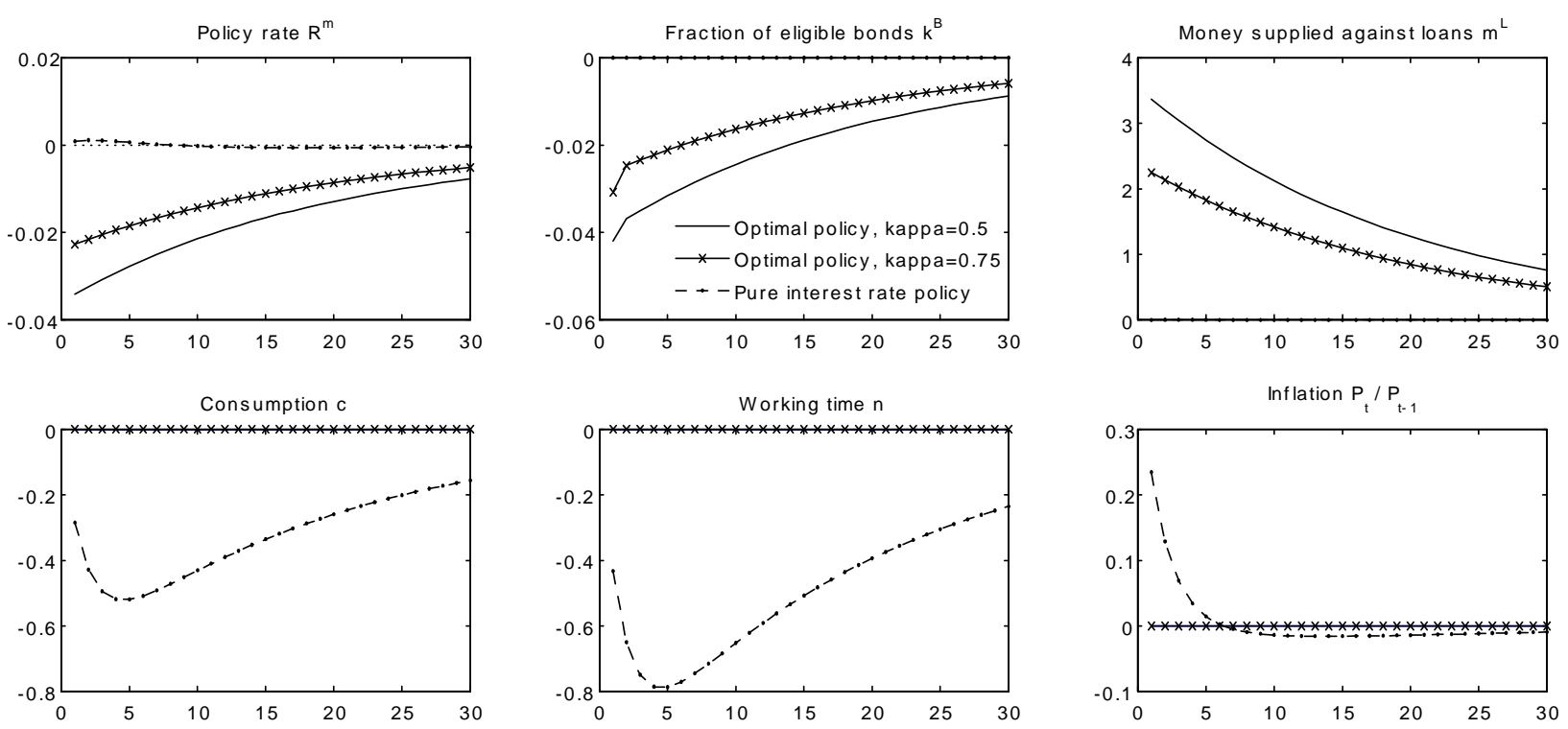

Figure 2: Responses to a one st. dev. mark-up shock (in \% dev. from steady state, and $R$ and $\kappa^{B}$ in absolute dev.)

from the New Keynesian literature. Inflation then increases on impact, while consumption and working time decrease as usual, though in a hump-shaped way. Under an optimal policy regime, the central bank instead lowers the policy rate to off-set the cost increasing effect of the mark-up shock. Like under productivity shocks, the policy rate is adjusted in a less pronounced way when more loans are eligible (see starred line). To stabilize consumption and working time at first-best levels, while facing an increase in loans (due to higher wage payments), the central bank reduces the fraction of accepted bonds $\kappa_{t}^{B}$. Hence, by adjusting the latter and the policy rate $R_{t}^{m}$, cost push shocks are completely neutralized.

\section{Discussion}

In this section, we first consider credit default risk and show that the central bank can avoid losses due to default by introducing haircuts. In the second part, we argue that collateralized central bank lending, as modelled in here, is not equivalent to direct central bank lending.

\subsection{Credit default and haircuts}

To account for credit risk, we model default in a very simple way. Specifically, we introduce random idiosyncratic productivity levels $\omega_{j, t}$ in the intermediate goods sector, which 
materialize after the labor market closes in subperiod 3 (see section 2.1). We assume that the realizations can be observed by borrowers and lenders without any (monitoring) costs, which would solely add costs/frictions that cannot be eliminated by monetary policy. We consider the following simple debt contract: A firm $j$, which exists for one period, offers a loan contract at the price $1 / R_{j, t}^{L}$ that leads to a pay-off of 1 when it is able to meet this payment, i.e. when its productivity level is sufficiently high $\omega_{j, t} \geq \bar{\omega}_{j, t}$, where $\bar{\omega}_{j, t}$ is the minimum productivity level that enables full repayment. Otherwise, $\omega_{j, t}<\bar{\omega}_{j, t}$, firm $j$ goes bankrupt and pays out its total revenues. Neglecting the wage subsidy, for simplicity, the maximization problem of an intermediate goods producing firm $j$ can be written as $\max E\left[\left(P_{J, t} / P_{t}\right) \omega_{j, t} a_{t} n_{j, t}^{\alpha}-w_{t} n_{j, t}-l_{j, t}\left(R_{j, t}^{L}-1\right) / R_{j, t}^{L}\right]$, s.t. (1), where the expectations are based upon the information at the beginning of the period after aggregate state variables (but not the $\omega_{j, t}^{\prime} s$ ) are already realized.

Since firms are ex-ante identical, loan contracts for different firms are signed at the same rate $R_{j, t}^{L}=R_{t}^{L}$. After workers are paid, firms draw idiosyncratic productivity levels from the same time invariant distribution with density function $f\left(\omega_{j, t}\right)$ and a mean of one, $E\left(\omega_{j, t}\right)=1$. Hence, the conditions (6)-(7) hold (for $\tau^{n}=0$ ) and all firms behave in an identical way. In particular, they all hire labor according to $q_{t} a_{t} \alpha n_{t}^{\alpha-1}=w_{t} R_{t}^{L}$, where $q_{t}=P_{J, t} / P_{t}$, and borrow $l_{t} / R_{t}^{L}=w_{t} n_{t}$. After the idiosyncratic productivity shock is realized, a firm $j$ fully repays loans $l_{t}=\alpha q_{t} a_{t} n_{t}^{\alpha}$ if $\omega_{j, t} \geq \alpha$ or, if $\omega_{j, t}<\alpha$, lenders get $\omega_{j, t} q_{t} a_{t} n_{t}^{\alpha}$. The expected pay-off for a lender is therefore $\int_{\alpha}^{\infty} \alpha q_{t} a_{t} n_{t}^{\alpha} f\left(\omega_{j, t}\right) d \omega_{j, t}+\int_{-\infty}^{\alpha} \omega_{j, t} q_{t} a_{t} n_{t}^{\alpha} f\left(\omega_{j, t}\right) d \omega_{j, t}$ and the expected rate of repayment $1-\delta^{e}$ equals:

$$
1-\delta^{e}=\int_{\alpha}^{\infty} f\left(\omega_{j, t}\right) d \omega_{j, t}+\alpha^{-1} \int_{-\infty}^{\alpha} \omega_{j, t} f\left(\omega_{j, t}\right) d \omega_{j, t} .
$$

Firms drawing a productivity level that exceeds $\alpha$ transfer their profits to the households. Households will only invest in loans if they are compensated for expected losses due to default. Likewise, the central bank can react to default induced expected changes in the price of loans by introducing haircuts $h$, when it accepts loans as collateral:

$$
M_{t}^{L} \leq(1-h)\left(\kappa_{t} L_{t} / R_{t}^{m}\right)
$$

Hence, choosing sufficiently large haircuts can shield against central bank losses when its 
counterparty (households) refuses to repurchase the loan at the non-default value. The haircut exactly compensates for losses if $h=\delta^{e}$. If, for example, $\omega_{j, t}$ is uniformly distributed and the labor income share equals $\alpha=0.66$, then this amounts to a haircut of 6.5 b.p. (24 b.p), when $2.5 \%(5 \%)$ of all intermediate goods producing firms default in each period.

Accounting for credit default and haircuts $h=\delta^{e}$, leads to a RE equilibrium that differs only by the loan rate satisfying $R_{t}^{L}=\left(1-\delta^{e}\right)^{-1}\left\{\left(1-\kappa_{t}\right) \beta E_{t}\left[\left(c_{t+1}^{-\sigma} / c_{t}^{-\sigma}\right) \pi_{t+1}^{-1}\right]+\kappa_{t} / R_{t}^{m}\right\}^{-1}$ instead of (34), which exceeds the loan rate for the risk-free case by $\left(1-\delta^{e}\right)^{-1} \cdot{ }^{23}$ The higher loan rate tends to raise the costs of borrowing and therefore to lower aggregate production, such that the long-run first best allocation can - even for $R^{m}=1$ - not be implemented (see proposition 3). Nevertheless, the central bank can efficiently stabilize the economy in the neighborhood of a steady state, like in the case of risk-free loans (see propositions 4 and 5), as long as the loan rate is linked to the policy rate through $\kappa_{t}>0$. Hence, the central bank can enhance welfare by using all instruments as described in the previous sections, while it can avoid losses by using haircuts.

\subsection{Direct central bank lending}

Suppose that the central bank would conduct credit policy, i.e., it would supply loans directly to intermediate goods producing firms at the policy rate, rather than lend to households against firm loans as collateral. As long as the central bank does not lend to all firms but only to a fraction $\kappa<1$, firms who borrow from households will face higher costs of borrowing than firms receiving loans directly from the central bank, if it sets the policy rate below the consumption Euler rate, $R_{t}^{m}<R_{t}^{d}$. As a consequence, a fraction $\kappa$ of intermediate goods producing firms, who can borrow at the policy rate, will hire more workers and produce at a higher level, than firms borrowing from households at the rate $R_{t}^{L}=R_{t}^{d}$. Such a policy would be equivalent to the case where the central bank announces which loans are accepted for repos before rather than after households lend to firms (as assumed in section 2.1). Hence, households would demand different loan rates from firms depending on whether debt issued by the particular firm is eligible or not.

In our set-up, the central bank avoids firms facing different costs of borrowing, by ran-

\footnotetext{
${ }^{23}$ Investments in loans then satisfy $R_{t}^{L}\left[\left(1-\delta_{t}^{e}\right) \lambda_{i, t}+\eta_{i, t}\left(1-h_{t}\right) \kappa_{t}\right]=R_{t}^{m}\left(\lambda_{i, t}+\eta_{i, t}\right)$ (instead of 15), which together with (12) and (14) leads to $R_{t}^{L}=c_{i, t}^{-\sigma} /\left\{\lambda_{i, t}\left[\left(1-\delta_{t}^{e}\right)-\left(1-h_{t}\right) \kappa_{t}\right]+c_{i, t}^{-\sigma}\left(1-h_{t}\right) \kappa_{t} / R_{t}^{m}\right\}$.
} 
domly choosing eligible loans after loan contracts are signed (see section 2.1). Due to this assumption, firms are identical when loan contracts are signed. Hence, the commonly raised critique that deviating from "Treasuries-only" distorts the credit allocation applies to credit policy, ${ }^{24}$ but not for collateralized central bank lending as modelled in this paper.

\section{Conclusion}

In contrast to the New Keynesian view on monetary policy, there exist additional instruments available for central banks beyond setting the policy rate, which are available not only in crises times. Central banks typically ration money in open market operations, where money is essentially supplied in form of collateralized loans. While this has so far been neglected for the analysis of optimal monetary policy, our analysis shows how central banks can enhance welfare under optimal collateralized lending compared to a pure interest rate policy regime.

The main idea is that central banks are able to control the price as well as the quantity of money when it rations the supply of money. The price of money, i.e. the policy rate, can then differ from the consumption/savings rate, which allows to affect both, the supply side and the demand side, in a separate way. A prerequisite for an effective supply side instrument is that short-run corporate debt securities serve as substitutes for treasury securities, which are typically accepted as collateral. The central bank can then directly stabilize firms' marginal costs by controlling the costs of borrowing via the policy rate. At the same time, it can tighten/relax access to rationed money to stimulate/dampen aggregate demand consistent with potential output. Optimal central bank lending can thereby overcome the well-known monetary policy trade-off between stabilizing prices and closing output-gaps.

The model can further be applied for an analysis of effects on interest rates and macroeconomic aggregates of unconventional monetary policies at the zero lower bound, which have been applied during the recent financial crises by several central banks, and for the analysis of different exit strategies.

\footnotetext{
${ }^{24}$ Under direct lending and $\kappa<1$, firms face different loan rates, which can - depending on the labor income share - lead to an aggregate output of the intermediate goods sector that is smaller than in the case where all firms face the same costs of borrowing and produce at the same level.
} 


\section{References}

Adao, B., I. Correia, and P. Teles, 2003, Gaps and Triangles, Review of Economic Studies, 70, 699-713.

Atkeson, A., and P.J. Kehoe, 2009, On the Need for a New Approach to Analyzing Monetary Policy, NBER Macroeconomics Annual 2008, edited by D. Acemoglu, K. Rogoff and M. Woodford.

Benigno, P., and M. Woodford, 2004, Optimal Monetary and Fiscal Policy: A LinearQuadratic Approach, in: M. Gertler and K. Rogoff, eds., NBER Macroeconomics Annual 2003.

Bernanke, B.S., V. R. Reinhart, and B. P. Sack, 2004, Monetary Policy Alternatives at the Zero Bound: An Empirical Assessment, Brookings Papers on Economic Activity $35,1-100$.

Blinder, A.S., 2010, Quantitative Easing: Entrance and Exit Strategies, CEPS Working Paper no. 204.

Calvo, G., 1983, Staggered Prices in a Utility-Maximizing Framework, Journal of Monetary Economics 12, 383-398.

Canzoneri M.B., R. E. Cumby, and B.T. Diba, 2007, Euler Equations and Money Market Interest rates: A Challenge for Monetary Policy Models, Journal of Monetary Economics $54,1863-1881$.

Christiano, J.L., M. Eichenbaum, and C.L. Evans, 2005, Nominal Rigidities and the Dynamic Effects of a Shock to Monetary Policy, Journal of Political Economy 113, $1-45$.

Christiano, J.L., M. Trabandt, and K. Walentin, 2010, DSGE Models for Monetary Policy, Paper prepared for the Handbook of Monetary Economics, edited by B. Friedman and M. Woodford. 
Clarida, R., Galí, J., Gertler, M., 1999. The Science of Monetary Policy: A New Keynesian Perspective. Journal of Economic Literature 37, 1661-1707.

Correia, I., J.P. Nicolini, and P. Teles, 2008, Optimal Fiscal and Monetary Policy: Equivalence Results, Journal of Political Economy 116, 141-170.

Covitz D., and C Downing, 2007, Liquidity or Credit Risk? The Determinants of Very Short-term Corporate Yield Spreads, Journal of Finance 62, 2303-2328.

Curdia, V. and M. Woodford, 2010, The Central-Bank Balance Sheet as an Instrument of Monetary Policy, Paper prepared for Carnegie-Rochester Conference on Public Policy, April 2010.

Federal Reserve System Study Group on Alternative Instruments for System Operations, 2002, Alternative Instruments for Open Market and Discount Window Operations, Washington: Board of Governors of the Federal Reserve System.

Fleming, M. J., W. B. Hrung and F. M. Keane, 2010, Repo Market Effects of the Term Securities Lending Facility, Staff Reports 426, Federal Reserve Bank of New York.

Gali, J., M Gertler, and J. D. López-Salido, 2007, Markups, Gaps, and the Welfare Costs of Economic Fluctuations, Review of Economics and Statistics 89, 44-59.

Gertler, M. and P. Karadi, 2009, A Model of Unconventional Monetary Policy, Paper prepared for Carnegie-Rochester Conference on Public Policy, April 2010.

Gertler, M. and N. Kiyotaki, 2009, Financial Intermediation and Credit Policy in Business Cycle Analysis, Paper prepared for the Handbook of Monetary Economics, edited by B. Friedman and M. Woodford.

Goodfriend, M., 2010, Central Banking in the Credit Turmoil: An Assessment of Federal Reserve Practice, Paper prepared for Carnegie-Rochester Conference on Public Policy, April 2010. 
Justiniano, A. and G. E. Primiceri, 2008, The Time-Varying Volatility of Macroeconomic Fluctuations, American Economic Review 98, 604-41.

Khan, A., R.G. King, and A.L. Wolman, 2003, Optimal Monetary Policy, Review of Economic Studies 70, 825-860.

Longstaff, F.A., S. Mithal and E. Neis, 2005, Corporate Yield Spreads: Default Risk or Liquidity? New Evidence from the Credit Default Swap Market, Journal of Finance 60, 2213-2253.

Meulendyke, A.M., 1998, U.S. Monetary Policy and Financial Markets, Federal Reserve Bank of New York, New York.

Ravenna, F. and C.E. Walsh, 2006, Optimal Monetary Policy with the Cost Channel, Journal of Monetary Economics 53, 199-216.

Reynard, S. and A. Schabert, 2010, Modeling Monetary Policy, Working Papers 20104, Swiss National Bank.

Sarkar, A., and J. Shrader, 2010, Financial Amplification Mechanisms and the Federal Reserve's Supply of Liquidity During the Crisis, Staff Report no. 431, Federal Reserve Bank of New York.

Schmitt-Grohé, S., and M. Uribe, 2004, Optimal Fiscal and Monetary Policy Under Sticky Prices, Journal of Economic Theory 114, 198-230.

Schmitt-Grohé, S., and M. Uribe, 2006, Optimal Simple and Implementable Monetary and Fiscal Rules: Expanded Version, NBER Working Paper 12402.

Smets, F., and R. Wouters, 2007, Shocks and Frictions in U.S. Business Cycles: A Bayesian DSGE approach. American Economic Review 97, 586-606.

Woodford, M., 2003, Interest and Prices: Foundations of a Theory of Monetary Policy, Princeton: Princeton University Press. 


\section{Appendix}

\section{A Rational expectations equilibrium}

Based on definition 1, a RE equilibrium can be reduced by substituting out $\psi_{t}$ and $\eta_{t}, y_{t}$ and $P_{J, t}$ and $P_{t}$. A RE equilibrium is then given by a set of sequences $\left\{c_{t}, n_{t}, \lambda_{t}, m_{t}^{R}, m_{t}^{H}\right.$, $\left.b_{t}, b_{t}^{T}, l_{t}, w_{t}, m c_{t}, \tilde{Z}_{t}, s_{t}, \pi_{t}, R_{t}, R_{t}^{D}, R_{t}^{L}\right\}_{t=0}^{\infty}$ satisfying

$$
\begin{aligned}
& \mu_{t} \chi n_{t}^{\eta}=w_{t} c_{t}^{-\sigma} \\
& R_{t}^{L}=\left[\lambda_{t}\left(1-\kappa_{t}\right)+\kappa_{t} c_{t}^{-\sigma} / R_{t}^{m}\right]^{-1} c_{t}^{-\sigma}, \\
& \lambda_{t}=\beta E_{t}\left[c_{t+1}^{-\sigma} / \pi_{t+1}\right] \\
& \lambda_{t}=\beta R_{t} E_{t}\left[\left(\lambda_{i, t+1}\left(1-\kappa_{t+1}^{B}\right)+\kappa_{t+1}^{B} c_{t+1}^{-\sigma} / R_{t+1}^{m}\right) \pi_{t+1}^{-1}\right], \\
& \lambda_{t}=\beta R_{t}^{D} E_{t}\left[\lambda_{t+1} / \pi_{t+1}\right], \\
& c_{t}-\kappa_{t} l_{t} / R_{t}^{m}=m_{t}^{H}+m_{t}^{R}, \text { if } \psi_{t}=\left(R_{t}^{m}-1\right) \lambda_{t}+R_{t}^{m}\left(c_{t}^{-\sigma}-R_{t}^{m} \lambda_{t}\right)>0, \\
& \text { or } c_{t}-\kappa_{t} l_{t} / R_{t}^{m} \leq m_{t}^{H}+m_{t}^{R}, \text { if } \psi_{t}=0, \\
& \kappa_{t}^{B} b_{t-1} /\left(R_{t}^{m} \pi_{t}\right)=m_{t}^{H}-m_{t-1}^{H} \pi_{t}^{-1}+m_{t}^{R}, \text { if } \eta_{t}=c_{t}^{-\sigma}-R_{t}^{m} \lambda_{t}>0, \\
& \text { or } \kappa_{t}^{B} b_{t-1} /\left(R_{t}^{m} \pi_{t}\right) \geq m_{t}^{H}-m_{t-1}^{H} \pi_{t}^{-1}+m_{t}^{R}, \text { if } \eta_{t}=0, \\
& b_{t}-b_{t-1} \pi_{t}^{-1}=(\Gamma-1) b_{t-1}^{T} \pi_{t}^{-1}-R_{t}^{m}\left(m_{t}^{H}-m_{t-1}^{H} \pi_{t}^{-1}\right), \\
& m c_{t} a_{t} \alpha n_{t}^{\alpha-1}=\left(1-\tau^{n}\right) w_{t} R_{t}^{L}, \\
& l_{t} / R_{t}^{L}=w_{t} n_{t}, \\
& \tilde{Z}_{t}(\varepsilon-1) / \varepsilon=Z_{t}^{1} / Z_{t}^{2},
\end{aligned}
$$

where $Z_{t}^{1}=c_{t}^{-\sigma} y_{t} m c_{t}+\phi \beta E_{t} \pi_{t+1}^{\varepsilon} Z_{t+1}^{1}$ and $Z_{t}^{2}=c_{t}^{-\sigma} y_{t}+\phi \beta E_{t} \pi_{t+1}^{\varepsilon-1} Z_{t+1}^{2}$,

$$
\begin{aligned}
1 & =(1-\phi)\left(\tilde{Z}_{t}\right)^{1-\varepsilon}+\phi \pi_{t}^{\varepsilon-1}, \\
m_{t}^{R} & =\Omega_{t} m_{t}^{H} \\
b_{t}^{T} & =\Gamma b_{t-1}^{T} / \pi_{t}, \\
c_{t} & =a_{t} n_{t}^{\alpha} / s_{t} \\
s_{t} & =(1-\phi) \tilde{Z}_{t}^{-\varepsilon}+\phi s_{t-1} \pi_{t}^{\varepsilon},
\end{aligned}
$$

the transversality conditions, a monetary policy setting $\left\{R_{t}^{m} \geq 1, \kappa_{t}^{B}, \kappa_{t} \in[0,1]\right\}_{t=0}^{\infty}, \Omega_{t}>0$ and $\pi \geq \beta$, for given $\left\{a_{t}, \mu_{t}\right\}_{t=0}^{\infty}$, initial values for public liabilities and $s_{-1}=1$. 
When money supply is not effectively rationed due to a non-binding open market constraint, which is equivalent to a lump-sum money supply with an irrelevant stock of government bonds, a RE equilibrium can further be reduced and redefined as follows.

Definition 2 For a non-binding open market constraint, $\eta_{t}=0$, a RE equilibrium is a set of sequences $\left\{c_{t}, n_{t}, l_{t}, w_{t}, m c_{t}, \tilde{Z}_{t}, Z_{t}^{1}, Z_{t}^{2}, s_{t}, \pi_{t}, R_{t}^{L}\right\}_{t=0}^{\infty}$ satisfying $\mu_{t} \chi n_{t}^{\eta}=w_{t} c_{t}^{-\sigma}$, $c_{t}^{-\sigma}=\beta R_{t}^{m} E_{t}\left[c_{t+1}^{-\sigma} \pi_{t+1}^{-1}\right], R_{t}^{L}=R_{t}^{m}$, (57)-(60), (63)-(64), the transversality conditions, $a$ monetary policy setting $\left\{R_{t}^{m} \geq 1\right\}_{t=0}^{\infty}$ and the inflation target $\pi \geq \beta$, for given sequences $\left\{a_{t}, \mu_{t}\right\}_{t=0}^{\infty}$ and $s_{-1}=1$.

Consider the version of the model with a non-binding open market constraint (see definition 2) for an inflation target equal to one. Then, a log-linear approximation of the model at the steady state (where $\widehat{x}_{t}$ denotes the percent deviation of a generic variable $x_{t}$ from its steady state value $\left.x: \widehat{x}=\log \left(x_{t}\right)-\log (x)\right)$ can easily be reduced to an aggregate demand condition $\sigma \widehat{y}_{t}=\sigma E_{t} \widehat{y}_{t+1}-\widehat{R}_{t}+E_{t} \widehat{\pi}_{t+1}$, an aggregate supply condition $\widehat{\pi}_{t}=\beta E_{t} \widehat{\pi}_{t+1}+$ $\chi \widehat{R}_{t}+\chi_{y} \widehat{y}_{t}+\chi \widehat{\mu}_{t}-\chi_{a} a_{t}$, where $\chi=(1-\phi)(1-\beta \phi) / \phi>0, \chi_{y}=\chi\left[(1+\eta) \alpha^{-1}+\sigma-1\right]>0$ and $\chi_{a}=\chi(1+\eta) / \alpha>0$, and a monetary policy $\left\{\widehat{R}_{t} \geq 1\right\}_{t=0}^{\infty}$, which is equivalent to Ravenna and Walsh's (2006) model and differs from a standard New Keynesian model (see Clarida el al., 1999) only by $\widehat{R}_{t}$ entering the aggregate supply condition.

\section{B Steady state}

In this appendix, we analyze the steady state of the model in detail (constant steady state values will not be indexed with a time index). The central bank determines $\kappa_{t}$, $\kappa_{t}^{B}$, and $\Omega_{t}$ as well as target values for the inflation rate $\pi \geq \beta$ and the policy rate $R^{m} \geq 1$. In a steady state, all endogenous variables grow with a constant rate, while the time-invariant policy targets have to be consistent with the steady state. We examine endogenous variables in a steady state for given policy target. Then, we will confirm that the target values (in particular the inflation target) are indeed consistent with the steady state.

For a given inflation target that equals the steady state inflation rate $\pi$, the conditions (59) and (60) imply $\tilde{Z}_{t}$ to be constant and to satisfy $\tilde{Z}=\left(\left(1-\phi \pi^{\varepsilon-1}\right) /(1-\phi)\right)^{1 /(1-\varepsilon)}$. The dispersion measure $s_{t}$ satisfying ( 64$)$, thus converges in the long run to

$$
s=\left[(1-\phi) /\left(1-\phi \pi^{\varepsilon}\right)\right]\left[\left(1-\phi \pi^{\varepsilon-1}\right) /(1-\phi)\right]^{-\varepsilon /(1-\varepsilon)}>0,
$$


if $\phi \pi^{\varepsilon}<1 \Leftrightarrow \pi<(1 / \phi)^{1 / \varepsilon}$ or $\pi=1$. Since $s$ is bounded from below and neither productivity nor labor supply exhibit trend growth, working time, output, and consumption cannot grow with a non-zero rate in the steady state, $y=c=n^{\alpha} / s$. Then, (59) implies that $Z_{t}^{2}$ converges to $Z^{2}=y^{1-\sigma} /\left(1-\phi \beta \pi^{\varepsilon-1}\right)$ if $\phi \beta \pi^{\varepsilon-1}<1 \Leftrightarrow \pi<[1 /(\phi \beta)]^{1 /(\varepsilon-1)}$. Given that $Z_{t}^{1} / Z_{t}^{2}$ and $Z_{t}^{2}$ are constant, and that (59) implies $Z^{1}=\frac{c^{1-\sigma} m c}{1-\phi \beta \pi^{\varepsilon}}$, real marginal costs are also constant,

$$
m c=[(\varepsilon-1) / \varepsilon] \tilde{Z}\left(1-\phi \beta \pi^{\varepsilon}\right) /\left(1-\phi \beta \pi^{\varepsilon-1}\right)
$$

Since steady state consumption is constant, (51) and (53) determine the long-run debt rate in the usual way, $R^{D}=\pi / \beta$. Condition (50) and (51) further imply the steady state loan rate to satisfy (29). Given that the loan rate, marginal cost, and working time are constant, (57) implies a constant steady state wage rate, $w=m c \alpha n^{\alpha-1} / R^{L}$.

Proof of proposition 1. Suppose that government bonds are eligible $\kappa_{B} \in(0,1]$, while loans are not eligible $\kappa=0$. The conditions (51) and (52) imply for the steady state $\lambda=\beta \frac{c^{-\sigma}}{\pi}$ and $\lambda=\beta R\left[\lambda\left(1-\kappa^{B}\right)+\kappa^{B} c^{-\sigma} / R^{m}\right] \pi^{-1}$, which can - together with $R^{D}=\pi / \beta-$ be combined to $R^{-1}=\left(R^{D}\right)^{-1}\left(1-\kappa^{B}\right)+\kappa^{B}\left(R^{m}\right)^{-1}$. For $\kappa_{B} \in(0,1]$ the government bond rate therefore satisfies $R \in\left[R^{m}, R^{D}\right)$. Eliminating $\psi_{t}$ in (14) with (12) and $\lambda_{t}$ with (51), leads to the steady state condition

$$
\eta=c^{-\sigma}\left(R^{m}-\beta / \pi\right) \geq 0
$$

which shows that the money market constraint $(2)$ is binding in the steady state $(\eta>0)$ if monetary policy sets the policy rate below the private debt rate, $R^{m}<R^{D}=\pi / \beta$. Further combining $\lambda=c^{-\sigma} \beta / \pi$ and (12) to

$$
\psi=c^{-\sigma}(1-\beta / \pi) \geq 0
$$

shows that the goods market constraint $(3)$ is binding in the steady state $(\psi>0)$ if the central bank sets its inflation target according to $\pi>\beta$.

When the central bank sets its targets according to $\pi>\beta$ and $R^{m}<\pi / \beta$, the constraints in the goods market and in the money market are binding (see proposition 1 ). The binding goods market constraint (54) and the central bank's money supply (61) then imply that 
steady state real balances held outright and held under repurchase agreements satisfy

$$
m_{t}^{H}=\left(c-\kappa l / R^{m}\right) /\left(1+\Omega_{t}\right) \quad \text { and } \quad m_{t}^{R}=\left(c-\kappa l / R^{m}\right) \Omega_{t} /\left(1+\Omega_{t}\right) .
$$

Household's money holdings evolve in the steady state according to $m_{t}^{H}+m_{t}^{R}=\frac{m_{t-1}^{H}}{\pi}+$ $\frac{\kappa_{t}^{B} b_{t-1} / \pi}{R^{m}}$ (see 55 ), which implies household steady state bond holdings to satisfy

$$
\kappa_{t}^{B} b_{t-1}=\bar{c} \pi\left[1-\pi^{-1}\left(1+\Omega_{t-1}\right)^{-1}\right] R^{m},
$$

where $\bar{c}=c-\kappa l / R^{m}$. In the steady state, the total supply of government bonds satisfies $b_{t}^{T} / b_{t-1}^{T}=\Gamma \pi^{-1}$ (see 62). The evolution of household bond holdings is constrained by (56), which can by substituting out real balances with (69) and total bonds $b_{t}^{T}$ be rewritten as:

$$
b_{t}-b_{t-1} \pi^{-1}=(\Gamma-1) b_{t-1}^{T} \pi^{-1}-R^{m} \bar{c}\left[\left(1+\Omega_{t}\right)^{-1}-\pi^{-1}\left(1+\Omega_{t-1}\right)^{-1}\right] .
$$

These steady state conditions impose constraints on the steady state inflation rate, which has to equal the inflation target.

Proof of proposition 2. Suppose that $R^{m}<\pi / \beta$ and $\pi>\beta$, such that the goods and the open market constraint are binding. Eliminating household bond holdings $b_{t-1}$ and $b_{t}$ in (71) by (70), then leads to the following steady state condition for total bonds

$$
\begin{aligned}
\frac{\Gamma-1}{\pi \widetilde{c} R^{m}} b_{t-1}^{T}= & \frac{\pi}{\kappa_{t+1}^{B}}\left[1-\pi^{-1}\left(1+\Omega_{t}\right)^{-1}\right]-\frac{1}{\kappa_{t}^{B}}\left[1-\pi^{-1}\left(1+\Omega_{t-1}\right)^{-1}\right] \\
& +\left[\left(1+\Omega_{t}\right)^{-1}-\pi^{-1}\left(1+\Omega_{t-1}\right)^{-1}\right] .
\end{aligned}
$$

Any inflation target of the central bank has to be consistent with the demand (72) and the supply of government bonds (62), which equals $b_{t}^{T} \pi / b_{t-1}^{T}=\Gamma$ in the steady state. To establish long-run price stability, $\pi=1$, for which the RHS of (72) simplifies to $\left(1+\Omega_{t}\right)^{-1}\left[\left(\kappa_{t+1}^{B}\right)^{-1} \Omega_{t}+\right.$ $1]-\left(1+\Omega_{t-1}\right)^{-1}\left[\left(\kappa_{t}^{B}\right)^{-1} \Omega_{t-1}+1\right]$, we consider two cases:

First, suppose that $\Gamma \geq 1$ and that the share of money supplied outright is constant and satisfies $1+\Omega \geq 1$. Substituting out total bonds $b_{t}^{T}$ in (62) by (72) for $\pi=1$ then gives

$$
\left[\left(\kappa_{t+2}^{B}\right)^{-1}-\left(\kappa_{t+1}^{B}\right)^{-1}\right] /\left[\left(\kappa_{t+1}^{B}\right)^{-1}-\left(\kappa_{t}^{B}\right)^{-1}\right]=\Gamma
$$

which is satisfied for a constant growth rate of $\kappa_{t}^{B}$ satisfying $\kappa_{t}^{B}=\Gamma^{-1} \kappa_{t-1}^{B}$. 
Second, suppose that $\Gamma<1$ and that the fraction of eligible bonds is constant and satisfies $\kappa^{B}<1$. Substituting out total bonds $b_{t}^{T}$ in (62) by (72) for $\pi=1$ then gives

$$
\frac{\left(\Omega_{t}-\Omega_{t+1}\right) /\left[\left(1+\Omega_{t}\right)\left(1+\Omega_{t+1}\right)\right]}{\left(\Omega_{t-1}-\Omega_{t}\right) /\left[\left(1+\Omega_{t-1}\right)\left(1+\Omega_{t}\right)\right]}=\Gamma,
$$

which is satisfied for a share of money held outright $\left(1+\Omega_{t}\right)^{-1}$ satisfying $\left(1+\Omega_{t}\right)^{-1}=$ $\omega\left(1+\Omega_{t-1}\right)^{-1}$, where $\omega=\Gamma$. This establishes the claims made in the proposition.

Proof of proposition 3. The steady state conditions for the dispersion term (65) and for marginal costs (66) immediately show that long-run price stability, $\pi=1$, implies $s=1$ and $m c=1$. Using these values, steady state consumption, as given in (30), equals $c=\left[(\alpha / \chi) / R^{L}\right]^{\frac{\alpha}{1+\eta+\sigma \alpha-\alpha}}$. Since the steady state loan rate $R^{L}$ satisfies $(29)$, we know that $R^{L}=1$ if and only if all loans are eligible $\kappa=1$ and the policy rate is set at its zero lower bound $R^{m}=1$. In this case steady state consumption equals its first-best value, $c=(\alpha / \chi)^{\frac{\alpha}{1+\eta+\sigma \alpha-\alpha}}$. Given that $s=1,(63)$ implies that working time also equals its firstbest value $n=(\alpha / \chi)^{\frac{1}{\eta+\alpha \sigma+1-\alpha}}$.

\section{Stabilization policy}

Proof of proposition 4. For $R^{m}<\pi / \beta, \pi>\beta$, and $\phi=0$, (32)-(39) hold. Consider a sequence $\left\{\Omega_{t}\right\}_{t=0}^{\infty}$. Combining (32) and (35) to

$$
w_{t}=a_{t} \alpha n_{t}^{\alpha-1} \mu\left(R^{L} / R_{t}^{L}\right)
$$

and substituting out wages with (73) in (36), gives $\left(1+\Omega_{t}\right) m_{t}^{H}=c_{t}\left(1-\kappa \alpha \mu R^{L} / R_{t}^{m}\right)$, which can be used to eliminate real balances in (37) such that

$$
\pi_{t}=\frac{\left(\kappa_{t}^{B} b_{t-1} / R_{t}^{m}\right)+c_{t-1}\left(1-\kappa \alpha \mu R^{L} / R_{t-1}^{m}\right) /\left(1+\Omega_{t}\right)}{c_{t}\left(1-\kappa \alpha \mu R^{L} / R_{t}^{m}\right)}
$$

Substituting out expected inflation by (74) in (40), shows that the central bank can satisfy (40) by setting $R_{t}^{m}, \kappa_{t}$, and $\kappa_{t}^{B}$ according to (41). Then,

$$
R_{t}^{L} / R^{L}=\mu / \mu_{t}
$$

holds by (34), and (32) reduces to $a_{t} \alpha n_{t}^{\alpha-1}=\chi n_{t}^{\eta} c_{t}^{\sigma}$, which together with (33) imply the allocation to satisfy $n_{t}=n_{t}^{*}$ and $c_{t}=c_{t}^{*} \forall t \geq 0$, where $n_{t}^{*}$ and $c_{t}^{*}$ are given in (27). 
For a set of sequences $\left\{R_{t}^{m}, \kappa_{t},\left(\kappa_{t}^{B} b_{t-1}\right), \Omega_{t}\right\}_{t=0}^{\infty}$, which satisfy (41), and the allocation $\left\{c_{t}^{*}\right.$, $\left.n_{t}^{*}\right\}_{t=0}^{\infty}$, the loan rate is determined by (75), the wage rate by (73), and real money holdings by (36). The initial price level $P_{0}$ is then determined by $P_{0}=\left[\left(\kappa_{0}^{B} B_{-1} / R_{0}^{m}\right)+M_{-1}^{H}\right] /\left[\left(1+\Omega_{t}\right) m_{0}^{H}\right]$, where $B_{-1}>0$ and $M_{-1}^{H}>0$ are given. Since inflation $\pi_{t}=P_{t} / P_{t-1}$ is given by $\pi_{t}=$ $\left[\left(\kappa_{t}^{B} b_{t-1} / R_{t}^{m}\right)+m_{t-1}^{H}\right] /\left[\left(1+\Omega_{t}\right) m_{t}^{H}\right] \forall t \geq 1$, where $b_{0}$ is predetermined by $b_{0}=\left[\left(B_{-1}+\right.\right.$ $\left.\left.(\Gamma-1) B_{-1}^{T}+R_{0}^{m} M_{-1}^{H}\right)\left(1+\Omega_{t}\right) P_{0}^{-1}-R_{0}^{m}\right] m_{0}^{H}$ and $b_{t-1} \forall t \geq 2$ by (38), the price level sequence $\left\{P_{t}\right\}_{t=0}^{\infty}$ is uniquely determined.

Proof of proposition 5. Combine (35) and (42), to eliminate wages in (36), such that $\left(1+\Omega_{t}\right) m_{t}^{H}=c_{t}\left(1-\kappa_{t} m c_{t} s_{t} \alpha \mu R^{L} / R_{t}^{m}\right)$, where we used (43). The binding money market constraint (37), can then be written as $\kappa_{t}^{B} b_{t-1} \pi_{t}^{-1}=R_{t}^{m}\left[c_{t}\left(1-\kappa_{t} s_{t} m c_{t} \mu_{t} \alpha R_{t}^{L} / R_{t}^{m}\right)-m_{t-1}^{H} \pi_{t}^{-1}\right]$. Hence, the central bank implements $\widetilde{c}_{t}$ and $\widetilde{n}_{t}$ by adjusting the amount of eligible bonds according to (47). Further setting the policy rate according to (40) for $\kappa_{t}>0$, such that the loan rate off-sets mark-up shocks, implies $m c_{t}=1$ by (42) and (43), $\pi_{t}=1$ by (45), $s_{t}=1$ by (44), and thus $\widetilde{c}_{t}=c_{t}^{*}$ and $\widetilde{n}_{t}=n_{t}^{*}$ by $(46)$.

For $\kappa_{t}=0$, (40) reduces to $\beta E_{t}\left(c_{t+1} / c_{t}\right)^{-\sigma} \pi_{t+1}^{-1}=\mu_{t} /\left(\mu R^{L}\right)$, which cannot be satisfied under first-best, since inflation then must equal one (see 44 and 45) and consumption not a function of mark-up shocks (see 27). 